\title{
WestVirginiaUniversity
}

THE RESEARCH REPOSITORY @ WVU

Graduate Theses, Dissertations, and Problem Reports

2003

\section{Development of instrumentation for acoustic monitoring}

Deepak Mehra

West Virginia University

Follow this and additional works at: https://researchrepository.wvu.edu/etd

\section{Recommended Citation}

Mehra, Deepak, "Development of instrumentation for acoustic monitoring" (2003). Graduate Theses,

Dissertations, and Problem Reports. 1362.

https://researchrepository.wvu.edu/etd/1362

This Thesis is protected by copyright and/or related rights. It has been brought to you by the The Research Repository @ WVU with permission from the rights-holder(s). You are free to use this Thesis in any way that is permitted by the copyright and related rights legislation that applies to your use. For other uses you must obtain permission from the rights-holder(s) directly, unless additional rights are indicated by a Creative Commons license in the record and/ or on the work itself. This Thesis has been accepted for inclusion in WVU Graduate Theses, Dissertations, and Problem Reports collection by an authorized administrator of The Research Repository @ WVU. For more information, please contact researchrepository@mail.wvu.edu. 


\title{
Development of Instrumentation for Acoustic Monitoring
}

\author{
Deepak Mehra \\ Thesis Submitted to \\ College of Engineering and Mineral Resources \\ at West Virginia University \\ In partial fulfillment of the requirements \\ for the degree of \\ Master of Science \\ In \\ Aerospace Engineering \\ Dr. John Loth, Ph.D., Chair \\ Dr. Gary Morris, Ph.D. \\ Dr. Eric Johnson, Ph.D.
}

Department of Mechanical and Aerospace Engineering

Morgantown, West Virginia

2003

Keywords: Acoustics, Natural Gas, Leaks 


\section{ABSTRACT \\ Development of Instrumentation for Acoustic Monitoring}

\section{Deepak Mehra}

Natural gas conservation and availability depends on quick leak detection. Leaks may be caused naturally or by man made damage. Corrosion is one of the major causes of leaks since the average life of an underground gas pipeline is 50 years and the gas pipelines have been in use since late 1800s. This thesis describes a source/sink flow acoustic wave sensor for the identification of leaks in gas pipelines. One of the many type of signals associated with the high velocity gas flowing out of a hole in the pipeline is the ramp or step pressure drop. Gas pipelines can only be accessed at line shut off valves, which are typically located at regular intervals about $60 \mathrm{~km}$ apart. At these line shut-off valves there is a $1 / 2$ inch NPT access port available above ground. To obtain acoustic signals from the gas inside the pipeline, the instrumentation is best installed on the access valves. When a leak is being created, low frequency and low-pressure waves are emitted.

A large 3-inch diameter diaphragm was installed in an attempt to detect the low frequency waves associated with a leak. This diaphragm with source or sink flow through a $17 \mathrm{~mm}$ internal diameter pipe acts as a pressure signal amplifier. The diaphragm was calibrated in lab with the source flow. At high flow rate and $0.85 \mathrm{~mm}$ gap, the diaphragm used in the lab was able to hold a weight of 45 grams or $0.44 \mathrm{~N}$, which was seven times higher than the momentum force in the pipe. The holding weight decreased at lower flow rates with an increase in gap size between the diaphragm and a flat brass disc. With a gap of $1.14 \mathrm{~mm}$ the force on the diaphragm was found to be 5 grams or $0.05 \mathrm{~N}$. The experimentally determined diffuser pressure recovery factor ( $\mathrm{rd}$ ) was nearly constant over the entire flow rate/ holding weight range. Thus a large diameter diaphragm may provide a high aerodynamic amplification of the incoming acoustic signals and it may be possible to use such configurations in development of instrumentation for acoustic monitoring. Its performance with acoustic signals from real gas pipelines has not been tested.

The deflection of the diaphragm due to the amplified force can be measured with a strain gage whose voltage is proportional to this deflection. A microphone should be used to record high frequency sound generated by the fluid inside the transmission line. 


\section{Acknowledgements}

I express my sincere gratitude to Dr. John Loth for helping me to prepare myself for a professional career. I thank my committee members Dr. Gary Morris and Dr. Eric Johnson to be in the committee and for their help extended to me in all manners.

I would like to thank Richard Guiler and Jay Snider and all other people who have helped me in my masters program.

My family has helped me in every possible way to reach this stage and has always stood by me, thank you very much for everything. 


\section{Table of Contents}

Content $\quad$ Page

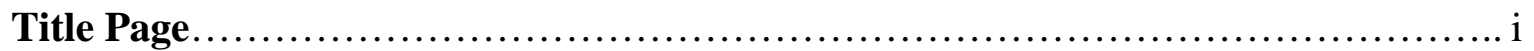

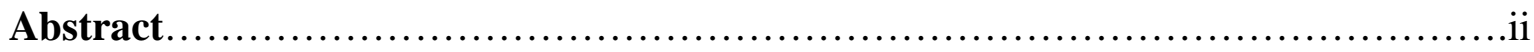

Acknowledgements....................................................... ii

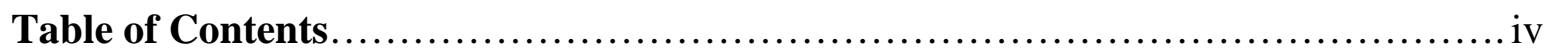

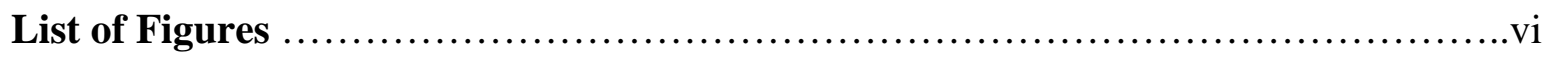

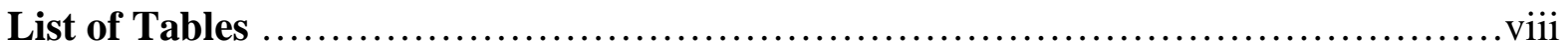

Chapter 1 Introduction.....................................................

1.1 Overview.............................................................

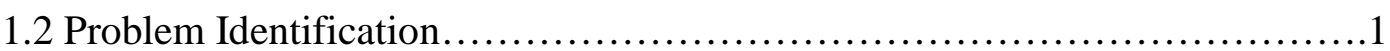

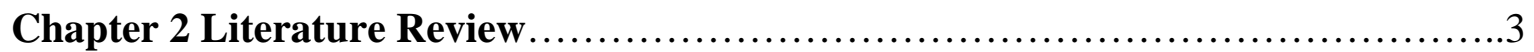

2.1 Natural Gas Transmission Pipelines......................................

2.2 Leaks..............................................................4

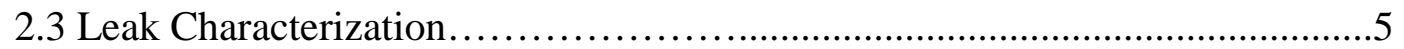

2.4 Non Acoustic Leak or Damage Detection Techniques.......................

Chapter 3 Acoustic Leak and Damage Detection Techniques.....................13

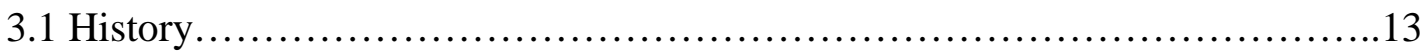

3.2 Past Research Done on Acoustic Leak Detection in Gas Pipelines...............15

3.3 Signal and its Representation.......................................22

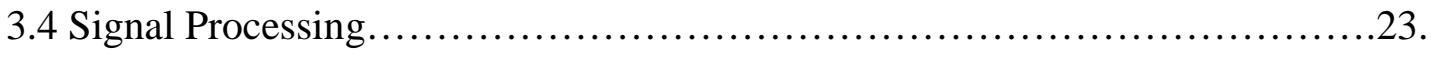


Chapter 4 Gas Pipeline Instrumentation. 25

4.1 WVU Venturi Type Acoustic Signal Amplifier Experimental Setup............25

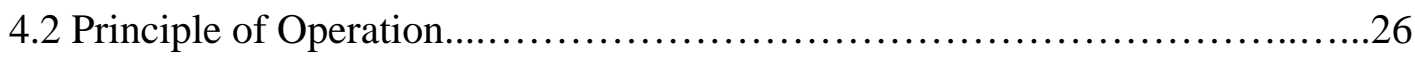

4.3 Ideal Friction Free Flow Source/Sink Acoustic Signal Amplifcation.............29

4.4 Force Calculations from Pressure Signals.....................................31

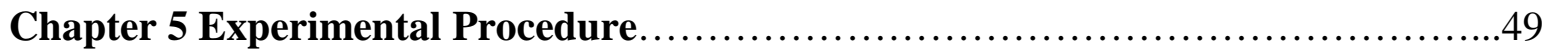

Chapter 6 Results and Conclusions............................................... 58

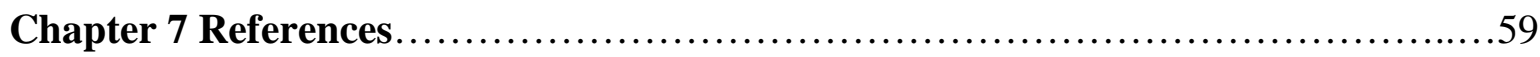




\section{List of Figures}

Figure 4.1: Source Flow Entering Though a $1 / 2$ Inch Port into a Gap between Two Flat

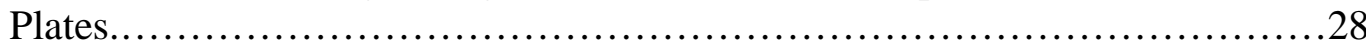

Figure 4.2: Sink Flow Leaving Through the Top of the $1 / 2$ inch Pipe Nipple................28

Figure 4.3: Picture of the Venturi Type Acoustic Signal Amplifier Housing................32

Figure 4.4: Stagnation Pressure in Pascal as a Function of Stagnation Pressure in dB.......35

Figure 4.5: 1/2 Inch Pipe Velocity Vo as a Function Stagnation Pressure in dB..............36

Figure 4.6: Flow Stagnation Force (N) in 1/2 Inch Pipe as a Function of Stagnation Pressure for Air Filled Line.

Figure 4.7: Flow Stagnation Force (Grams) 1/2 Inch Pipe as a Function of Stagnation Pressure for Air Filled Line...........................................................

Figure 4.8: Force $(\mathrm{N})$ on Diaphragm as a Function of Stagnation Pressure for Air Filled Line at $\mathrm{V} 2=\mathrm{Vo}$ 38

Figure 4.9: Force (Grams) on Diaphragm as a Function of Ramp Signal for Gap $=0.542 \mathrm{~mm}$ for Air Filled Line.

Figure 4.10: Air Flow Rate at 1 Atmospheres as a Function of Ramp Signal for a Gap of

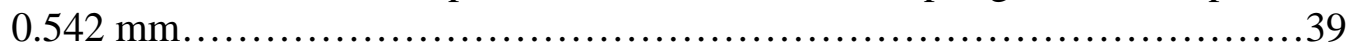

Figure 4.11: Diaphragm Force Amplification as a Function of Gap d ....................40

Figure 4.12: Force at Gap Equal $1 \mathrm{~mm}$ as a Function of Stagnation Pressure in $\mathrm{dB}$........40

Figure 4.13: Spherically Deflected Diaphragm.......................................41

Figure 4.14: 1/2 Inch Pipe Velocity Vo as a Function of Stagnation Pressure in dB at 1

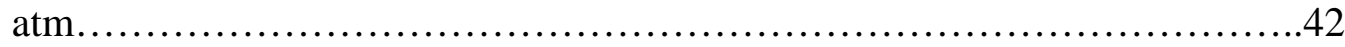

Figure 4.15: Methane Flow Rate at 10 Atmospheres as a Function of Stagnation Pressure for a

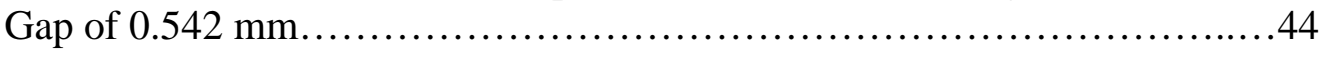

Figure 4.16: Flow Stagnation Force (N) in 1/2 Inch Pipe as a Function of Stagnation Pressure for Methane Filled Line.....................................................4

Figure 4.17: Flow Stagnation Force (Grams) in 1/2 Inch Pipe as a Function of Stagnation Pressure for Methane Filled Line .45 
Figure 4.18: Force (Grams) on the Diaphragm as a Function of Flow Stagnation Pressure in dB for Methane Filled Line

Figure 4.19: Force (N) on the Diaphragm as a Function of Stagnation Pressure for Methane Filled Line .46

Figure 4.20: Center Deflection of the Diaphragm as a Function of Acoustic Pressure.......46

Figure 5.1: Linearized Experimental Data Points.................................51

Figure 5.2: Change in inlet pressure Linearized Data Points........................52

Figure 5.3: Amplification as a function of weight................................53

Figure 5.4: Calculated Gap as a function of weight.................................53

Figure 5.5: Picture of diaphragm hanging freely with no airflow ......................54

Figure 5.6: Picture of diaphragm Suspended by Airflow with a weight of 43.5 grams.....55

Figure 5.7: Picture of diaphragm with a weight of 21 grams Suspended by Airflow.......56

Figure 5.8: Close view of diaphragm with a weight of 21 grams Suspended by airflow...57 


\section{List of Tables}

Table 2.1: Damage Recorded on Transmission Lines in the United States................4

Table 4.1: Table Showing Behavior of Outflow Velocity and Various Forces with Stagnation Pressure in an Air Filled Line........................................... 34

Table 4.2: Table Showing Behavior of Airflow Rate and Force with Stagnation Pressure in an Air Filled Line..........................................34

Table 4.3: Table Showing Behavior of Outflow Velocity and Various Forces with Stagnation Pressure in a Methane Filled Line............................35

Table 4.4: Table Showing Behavior of Airflow Rate and Force with Stagnation

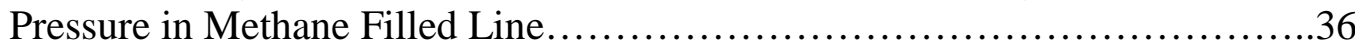

Table 4.5: Amplification Aamp as a Function of Gap d............................... 37

Table 4.6: Table Showing Variation of Deflection Angle, Force and Stress with Stagnation Pressure.........................................................43

Table 5.1: Table Showing Values Obtained From the Experiment......................50

Table 5.2: Experimental Values Converted to Metric Units............................51

Table 5.3: Calculated Values in Metric Units.......................................52 


\section{Nomenclature}

\begin{tabular}{|c|c|}
\hline $\mathrm{A}_{\mathrm{o}}$ & Pipe inlet/outlet area $\left(\mathrm{m}^{2}, \mathrm{~mm}^{2}\right)$ \\
\hline $\mathrm{A}_{1}$ & Inlet/outlet area $\left(\mathrm{m}^{2}, \mathrm{~mm}^{2}\right)$ \\
\hline $\mathrm{A}_{2}$ & Inlet /outlet area $\left(\mathrm{m}^{2}, \mathrm{~mm}^{2}\right)$ \\
\hline $\mathrm{A}_{\mathrm{r}}$ & Area at any diaphragm radius $r\left(\mathrm{~m}^{2}, \mathrm{~mm}^{2}\right)$ \\
\hline $\mathrm{A}_{\mathrm{amp}}$ & Force amplification rate \\
\hline $\mathrm{d}$ & Gap between diaphragm and brass plate (mm) \\
\hline $\mathrm{E}$ & Modulus of elasticity (GPa) \\
\hline EL & Elastic limit (MPa) \\
\hline Fo & Momentum force \\
\hline Fs & Suction force \\
\hline$\Delta \mathrm{P}$ & Pressure change associated with the creation of a leak (psia, N/m ${ }^{2}$ ) \\
\hline $\mathrm{P}$ & Pressure (psia, N/m²) \\
\hline $\mathrm{P}_{\text {ref }}$ & Reference pressure (psia, N/m²) \\
\hline $\mathrm{R}$ & Sphere radius (m, mm) \\
\hline$r_{2}$ & Diaphragm radius at the venturi inlet (mm) \\
\hline$r_{0}$ & Inlet port radius (mm) \\
\hline $\mathrm{r}_{1}$ & Diaphragm radius at the venturi outlet (mm) \\
\hline $\mathrm{T}$ & Temperature $(\mathrm{K})$ \\
\hline $\mathrm{t}$ & Diaphragm thickness (mm) \\
\hline Vol & Volume $\left(\mathrm{m}^{3}\right)$ \\
\hline $\mathrm{V}_{2}$ & Inlet/outlet velocity $(\mathrm{m} / \mathrm{s})$ at $\mathrm{r} 2$ \\
\hline $\mathrm{V}_{\mathrm{o}}$ & Velocity in the $1 / 2$ inch port $(\mathrm{m} / \mathrm{s})$ \\
\hline
\end{tabular}


$\mathrm{V}_{1}$

\section{Symbols}

$\delta$

$\mathrm{k}$

M

V

$\mathrm{R}$

$\rho$

$\sigma$

$\theta$

\section{Subscripts}

a

$\mathrm{m}$

1

2

o

ref

amp
Inlet/outlet velocity $(\mathrm{m} / \mathrm{s})$ at $\mathrm{r} 1$

Deflection (mm)

Specific heat ratio

Molecular weight $(\mathrm{kg} / \mathrm{kmol})$

Specific volume $\left(\mathrm{m}^{3} / \mathrm{kg}\right)$

Gas constant

Density $\left(\mathrm{kg} / \mathrm{m}^{3}\right)$

Stress $(\mathrm{Pa})$

Angle of deflection (radians)

Air

Methane

Inlet/outlet at inner radius

Inlet/Outlet at outer radius

$1 / 2$ inch nipple inlet/outlet

Reference

Amplification 


\section{Chapter 1}

\section{Introduction}

\section{Overview}

Natural gas is one of the major sources of energy not only in the United States but also in the rest of the world. Natural gas is processed in the field by natural gas processing units and then it is ready to be transported to consumers, which may be individual business units or residences. After processing, the natural gas is supplied to the utilities through transmission lines and further distributed by these utilities to the individual customers through small-metered pipes. Leaks in the pipeline systems are one of the major problems natural gas industry is suffering from. Leak cause loss of gas from the system and may also lead to a catastrophic explosion.

Leaks may be caused by corrosion, man-made damage called third party damage, or by nature during events like floods and earthquakes. Third party damage is a major cause of, pipeline rupture, leaks or damage finally leading to the formation of a leak. Such type of damage may be done by construction equipment or excavation by a third party in to the pipeline right of way. These damages may not appear immediately but eventually develop into a leak by corrosion inside stress fractures.

\section{Problem Identification}

Since the natural gas distribution has to deal with a vast network of gas pipelines spread all over the United States, it becomes necessary to have a quick leak identification mechanism. When the gas escapes from the piping due to a leak, it will saturate the ground around the pipe and migrate 
along conduits to other locations. The appearance of a rupture, leak or damage that could lead to a leak usually generates an acoustic signal, which can produce a transducer output ranging from several micro volts to several volts. This document will describe past research done by various researchers to detect this acoustic signal. The acoustic signal generated by the leak travels through the pipe wall, through gas inside the pipe and through the fluid medium outside at the leak location. This research also describes the calibrations of a source/sink flow acoustic signal amplifier, which is used to aerodynamically amplify the incoming acoustic signals from gas inside the pipeline. The instrument designed to aerodynamically amplify acoustic signals can be used at a $1 / 2$ inch NPT gas access port common on most lines. When a leak occurs, there is a small pressure drop, which forms a step or ramp type signal, which results in a temporary outflow from the housing back into the pipeline. Since the flow is very small and has short duration, detecting this event is very difficult. Therefore the source/sink flow acoustic amplifier is used to increase the deflection of a 3-inch diameter diaphragm. A sink flow is created between two 3-inch diameter flat surfaces installed in the source/sink flow acoustic signal amplifier, which speeds up as it approaches the center. This results in a suction force similar to that in the throat of a venturi. This force is many times greater than the momentum of the flow inside a $1 / 2$ inch nipple on the centerline. The force amplification depends on the gap used. The radial inflow or outflow acts as venturi. A strain gauge used in conjunction with the movement of the diaphragm gives a voltage, which is proportional to its deflection.

The diaphragm was calibrated in the lab with source flow. Experimental results confirmed that the aerodynamic amplification of acoustic signals can be obtained if the flow is guided through a gap between the diaphragm and a flat disc (brass disc in this case). 


\section{CHAPTER 2}

\section{Literature Review}

\subsection{Natural gas transmission pipelines}

Gas pipelines cover wide geographic areas and are spread all over the United States. About thirty percent of the energy produced in the US comes from natural gas supplied through more than a million miles of transmission lines. Many gas pipelines, which were installed in late 1800s, are still in existence and are used actively. According to Parker (1981) there was a rapid increase in the growth of natural gas distribution systems in the US in the 1900s especially from the 1940s to 1970s. About 12 billion standard cubic feet of natural gas per day is produced from offshore facilities. Natural gas produced by the offshore facilities also has to be transported to onshore processing facilities. Most of this is done through more than 20,000 miles of sub-sea pipelines. Transmission lines are typically made of steel, around 85\% of all the active pipelines in 1975 were made of steel. Other materials used in construction of gas pipelines include cast iron and plastic. Cast iron is used in the urban systems. Use of plastic as a gas pipeline started as early as 1961 and by 1975 there were around 94,000 miles of plastic pipelines.

Natural gas transmission lines operate at high pressure. Often friction pressure drop is associated with distance. Thus to compensate for this loss, turbine driven or reciprocating engine driven compressors are located at regular intervals, which keeps the gas moving through the system. 


\subsection{LEAK}

Any unintentional outflow of gas from a pipeline may be termed as a leak. Leaks can have different causes that may be man made or natural. Leaks, not identified immediately, can lead to an explosion. The maximum age of gas pipelines is estimated to be around 50 years with average age being 35 years. Parker gave an interesting statistic in his paper that on an average a 50 year old pipe will generate annually one reportable incident per 1680 miles. Pipes buried for 35 years generate half this rate and the pipes buried for 10 years generate one tenth of this rate. In one of the Office of Pipeline Safety data analysis it was found that the total number of leaks repaired increased by $50 \%$ from 1971 to 1975 .

\begin{tabular}{|l|l|}
\hline Mechanical Damage Caused & Percentage \\
\hline By Equipment & $44.0 \%$ \\
\hline Stress Corrosion Cracking & $1.5 \%$ \\
\hline Pitting Corrosion & $13.5 \%$ \\
\hline General Corrosion & $9.0 \%$ \\
\hline Chemical Bacterial & $4.0 \%$ \\
\hline Material Defect & $12.5 \%$ \\
\hline Construction and Upgrade & $7.5 \%$ \\
\hline Earth Movement, Washout, etc. & $8.0 \%$ \\
\hline
\end{tabular}

Table 2.1: Third party damage recorded on transmission lines in the United States (1994).

As evident from above data leaks can be caused due to a number of reasons. Even relatively small holes in high-pressure gas pipelines can produce dangerous clouds of gas eventually leading to an explosion. Leaks are usually classified according to the urgency of repair based on the potential danger. They are typically classified into three groups, (Huebler, 2000).

1. Those that need repair in $24-48$ hours,

2. Those that need repair in 30 days 
3. Those that don't need immediate repair but need to be monitored constantly

\subsection{Leak Characterizations}

The amplitude, frequency spectrum and the attenuation behavior of a leak signal traveling through a pipe wall are all a function of the pipe wall material properties (Bassim 1994). If the damage causes a sudden leak, then the associated rapid change in fluid pressure produces a pressure transient, often referred to as a burst signal. The supersonic jet of escaping gas contains acoustic energy. This type of emission is a continuous emission and has a wide frequency spectrum, $1 \mathrm{kHz}-1 \mathrm{MHz}$. The majority of this is confined to moderately high frequency portion of $175 \mathrm{kHz}$ to $750 \mathrm{kHz}$ (Shack, 1980).

Passive acoustic leak detection in pipelines makes use of the vibrational energy emitted by the straining or fracturing pipe wall material or by the acoustic energy associated with high pressure gas escaping through a perforated or ruptured wall. It is possible to detect an infringement event along a pipeline by properly interpreting the acoustic signature of the phenomena described above. The main challenge is to accurately isolate the acoustic signature of an infringement from the background noise within the pipeline environment such as pumping noise, flow turbulence noise, valve actuation etc. Details of the infringement-generated noise (acoustic signature) must be fully known along with the background noise with in the pipeline so as to enable separation between these two noises. The second challenge is to detect the acoustic signature far away from its signal source since the acoustic wave amplitudes are attenuated within the pipeline. It may be noted that the acoustic signature of the leak is unique but difficult to obtain. 
The frequency of the acoustic signals transmitted via the pipe wall, such as structural fracturing of the pipe wall and the sound of the escaping gas can range well into hundreds of kilohertz. The acoustic signal frequencies transported by the gas travel much slower than those via the pipe wall. However, due to the intimate contact of the pipeline with the backfill material, the longitudinal transmission of the higher frequency components of the acoustic energy within the wall material is highly damped and does not travel any significant distance from the location of the source of the acoustic signal. Transmission of acoustic signals through gas suffers damping in proportion to the square of the signal frequency. Wall damping effects, viscous effects and molecular relaxation effects all contributes to the attenuation of the strength of the high frequency signal. Acoustic studies in the past have made it apparent that although the acoustic signals of a pressurized fluid escaping through a leak may include a wide range of frequencies, only relatively low frequencies can travel sufficiently long distances to be useful for practical leak detection methods. This happens due to significant attenuation of the higher frequency components. In his paper on acoustic leak detection Rocha says that the acoustic frequencies on the order of $10 \mathrm{~Hz}$ can propagate in a gas for distances on the order of 100 miles. The local pressure drop due to the leak is a function of the static pressure in the pipe at the leak site, the diameter of the leak hole and the local diameter of the pipe. The detectable acoustic pressure of a leak can be as small as 5 millibars $(0.073 \mathrm{psi})$ in a pipeline with a static pressure of 69 bars (1000 psi), which requires sophisticated noise cancellation techniques to increase signal to noise ratio (Rocha, 1980). Eis, et al, 1998, conducted experiments to determine the distance in which an acoustic step function impact could be transmitted through the pipe wall in a 24-inch diameter pipeline. By dropping weights ranging from few pounds up to 90 pounds, the impact was 
detected up to 3.2 miles away. Researchers theorize that the impact could be detected as far as 25 miles away. Their theory also indicated that the signals with frequencies greater than $500 \mathrm{~Hz}$ were completely attenuated in their tests.

Bassim and Tangri (1994) performed their experiments to determine the effect of the attenuation of acoustic signals generated by strained or fractured pipe segments in the laboratory with both flowing and non-flowing helium gas. They also performed the experiments with a leak in the pipe segment. They found that the attenuation of the lower frequency signals was less than that of the high frequency signals and that the acoustic signal strength varied with leak hole size.

\subsection{Non Acoustic Leak Detection Techniques}

Non-acoustic leak detection techniques are an alternative to the acoustic leak detection methods. In many cases these may be simple and cheap to implement but usually have a large delay in detection. There can be different types of non-acoustic leak detection techniques, prominent among those are
a. Analysis with transient flow modeling
b. Human monitoring-sound, smell and visual
c. Pigging

\section{4. a Transient Flow Modeling Analysis:}

Long transmission pipelines have certain restrictions placed on their operation by state and federal codes. Stress limits are established for the pipe material, which sets the pressure limits in 
operation especially for transient cases. For optimum economic benefits from the pipeline, it is desirable to operate near maximum allowable stress conditions, as then the product velocity, friction pressure loss, and pumping power required are the minimum. Pipelines are generally constructed along terrain varying in elevation, so that the distance between pumping stations depends on elevation changes as well as suitable land available for the station. Therefore, numerical solutions of the transient behavior of long transmission lines are useful in a number of different application nodes. Some applications are quite natural, such as generating flow, pressure and temperature records, detection of instrument failures, batch tracking, and operator tracking.

If one considers the effect of a prolonged excessive demand, as with the case of a severe cold spell, the supply may not be adequate to hold all pressures to their customary values. By allowing the pressure to be reduced in the system, the amount of gas stored (line pack) is reduced making extra gas unavailable for consumption. Transient analysis is extremely useful from an operating viewpoint. The method of characteristics numerical solution is widely accepted as a way of analyzing transients (Wylie, 1993). The line pack method is an offline type method. Whereas other methods like flow balance method, real time transient method etc. are all on line type methods. Every transmission line operator uses a transient analysis code to monitor operations over the entire system. When interfaced with a SCADA (Supervisory Control and Data Acquisition) system, the opportunity to locate leaks is far superior to the mass balance based on steady state modeling. For suddenly developing large leaks there is a traveling pressure wave induced in the pipeline. Initially this wave is a step function, but with distance and due to friction this wave dissipates into a ramp function. To detect this rapid change in signal ramp rate 
requires monitoring the rate of change in $\mathrm{dp} / \mathrm{dt}$, which is the change in pressure with respect to time, instead of dp. SCADA's computerized monitoring system tracks pressure, velocities, pipeline geometry, chemical properties and temperature in a pipeline at various locations. This system calculates the flow balance as the difference between the metered flow leaving the pipe and metered flow coming into a section. In conjunction with the flow balance most SCADA systems incorporate transient modeling to simulate pressure changes that would accompany a fast onset leak. They are used on most large transmission lines today and are very reliable for large and fast onset leaks, but they have limitations. They can only be used for leaks with a magnitude of $0.5-10 \%$ of the flow and cannot detect leaks that have a slow initiation.

SCADA techniques have the advantage of providing a rapid response when there is a significantly fast onset leak (Jolly, 1992). One example of the complexity of one of these leak detection systems is an application in one of the United States large petroleum products pipeline systems. This pipeline system delivers about 500,000 barrels a day of product over an average of 520 miles to terminals in the southeastern and mid-Atlantic states. It includes 23 pipeline segments totaling over 3,000 miles and ranging in diameter from 6 inches to 30 inches. This system has 17 input points and 45 delivery points. The SCADA system monitoring this network has over 20,000 status points that must be scanned every several seconds. This complicated task is carried out by hubs of computers, which are each monitored by the hub master computer, which in turn communicates to a master computer (Kennedy, 1984). Thompson and Skogman used real time flow modeling for pipeline leak detection. They discuss the application of transient fluid flow and heat transfer models to a real time pipeline leak detection system on approximately 3100 miles of piping system with 60 pumping stations, 80 metering facilities and 
an accumulated pumping through all 24 pipelines of more than 1,000,000 barrels per day. Transient flow modeling and heat transfer models were used to calculate flow rates and pressure gradients, so the line inventory variations could be predicted. With the aid of a computer and real time operating data, these models make it possible to track batches, calculate flow rates and pressures and correct line inventories. The transient flow calculations also allow the prediction of flow rate differences between stations during transient flow. For transient fluid flow modeling it is necessary to solve the continuity, momentum equations and equation of state for natural gas. The transient pressure/ flow rate model sets boundary conditions equal to measured values of pressure at the endpoints of each section of the pipeline and then calculates a pressure/flow rate profile on the assumption that the line is leak free. Deviations between the measured and calculated values of flow rate at the pipeline endpoints as well as the differences between the calculated flow rates at booster stations are indicative of a leak in the pipeline.

Kiuchi (1993) in his paper presented a method for leak localization by considering flow rate and pressure profiles changing along a pipeline in a transient condition. In his paper he developed a method to determine the leak location using numerical and measured values of flow variables like density, flow rate and velocity. He used numerical techniques like the Lax-Wendroff method which is a time marching technique to find a variable at the $n+1$ time level using information from three available values of the same variable (in space) at the nth level. His analysis included several cases like steady flow and no consumer flow, changing outlet flows, steady flow with constant consumer flow, transient flow with constant consumer flows, and influence of instrument accuracy on the localization of leak. Kiuchi finally concluded in his paper that his equation which considers flow and pressure profiles along a pipeline identifies a more accurate 
leak position than the conventional equations for both steady state and transient conditions. This equation he concludes is also applicable to a pipeline having consumer stations, which causes abrupt change of flow rate profiles along the pipeline.

\section{4.b Direct Monitoring- Smell, Sound and Vision}

Direct monitoring means direct inspection by humans, which may include identifying a leak by smell, sound or even by the naked eye. Periodic line walking, driving or flying is used to try to observe the signs of a leak. Human vision can be used to look for discolored soil, leaking gas, gas bubbles coming up through standing water or in conjunction with thermal imaging or Schileren optics. Death of vegetation is one of the examples of visual leak detection. The human sense of smell can detect the odor associated with the gas. A well-trained person can smell the

additives in natural gas down to one part per million (ppm). Human hearing itself or with the aid of a stethoscope can also detect the frequency content in the audible range. Although this technique is commonly used and effective with highly trained technicians, the listener must be very close to the leak to hear it. Since this technique involves walking along a pipeline for detection of a leak this way is used infrequently.

\section{4.c Pigging}

Pipeline pigs and spheres are sensing devices that have been developed and used since the late 1960's. These instruments can be run anytime without interrupting the pipeline operation. A pig usually has a metal body with rubber or plastic end-caps and they are forced through the pipeline 
by the pressure of the flowing fluid. Pigs are periodically run through pipelines for integrity monitoring or leak detection. The magnetic flux leakage method or ultrasonic method is commonly used for integrity monitoring (Varma 2002). According to Flournoy and Schroeder at a frequency of about $35 \mathrm{kHz}$ the ratio of sounds produced by leaks of various configurations to the fluid and pig motion noise is highest. Magnetic flux leakage method involves the application of a magnetic field to the inside of the pipe wall. When corrosion or other degradation exists in the wall the pipe wall thickness is reduced and these areas therefore cannot carry as much magnetic flux as a full wall thickness area can carry (Varma, 2002). Pigs can also be fitted with ultrasonic sensors to inspect the pipe walls. The most common usage of ultrasonics is to measure wall thickness. A new method of ultrasonic testing is being developed and is called the electromagnetic acoustic transducer (EMAT) wave generator. An electrical current is generated near the pipe surface, which induces a magnetic field that in turn induces an electromagnetic force. The combination of forces in the material generates shear and longitudinal waves in the material that have certain characteristics for specific materials (Varma, 2002). Pigs have the capability of identifying areas, which may be prone to leakage and may be able to detect leaks in their vicinity, but they must actually travel through the pipeline and this may cause a large delay in the detection of a leak. 


\section{Chapter 3}

\section{Acoustic Leak and Damage Detection Techniques}

\subsection{History}

Leaks in the pipeline allow the fluid to escape, which generates noise. This acoustic emission from a leak in a pipeline provides an efficient method for continuous surveillance of pipelines for leak detection. The acoustic signals could be observed to identify a leak. Attempts to develop these leak detection techniques started as early as 1930's. Ultrasonic acoustic detection has been found very useful in locating pipeline leaks when one gets close to the source of a leak. This type of detection gives an attractive technique for online monitoring of pipelines.

The cost of repairing a damaged gas pipeline due to a leak is very high and to add to this the cost of the gas lost makes it very expensive to have a leak. The high hazard incidents occurring due to a leak, occur infrequently but when they occur, the cost per incident is much higher than a routine leak repair. Parker in his paper on leak detection states that the cost of repairing corrosion induced leaks will be close to one billion dollars which did not include the value of gas lost. The cost of gas lost per 1000 feet increased from $\$ 0.70$ to $\$ 2.80$ in 1980 and reached $\$ 5.00$ in the $21^{\text {st }}$ century. For a utility with 7000 miles of distribution lines, about four major incidents will occur in a day's time. The first systematic attempt to develop an improved means of leak detection combining both active and passive approaches was initiated late in 1950 and continued through 1965. The American Gas Association (AGA) supported these efforts and the technical work was carried out at the Institute of Gas Technology (IGT). This record of developing into an operational system is contained in two publications, "A New Approach to Pinpointing Gas Leaks 
with Sonics", 1961 and "Field Results with Sonic Pinpointing", 1964. The latter one says about the difficulties involved in the technology transfer to operating people largely unskilled in the use of employed electronic instrumentation. Larsen in 1939 raised the same point while making efforts to use a geophone for leak detection when he stated: "Thus far the best results have been obtained from operators who have had some college training along engineering lines. Analysis of the results of the extensive field measurements data indicated that the main problem was the unpredictable performance of the system, coupled with the inability to predict quantitatively the change of success or failure in a given situation."

Jolly after reviewing several acoustic based leak detection methods found that the most promising method is the low frequency impulse detection method. With the sensors mounted at the ends of the pipeline this method could capture the transient acoustic event associated with a rapid rupture of the pipeline. This method could detect leaks more than an inch in diameter but over a large distance of up to $100 \mathrm{~km}$. Small leaks that grow over a considerable period of time could not be detected by this method. He noted that the noise range of leaks is typically in the range of 5 to $300 \mathrm{kHz}$, when the sensors are mounted on the outside of the pipe. The detection range is not very high for this technique and therefore is used only in industrial plants. Parker says that the acoustic signal emitted by gas flowing out of the leak contains the background noise in itself. Therefore the signal to noise ratio of the detected acoustic signal must be a maximum to obtain the best possible information about the leak.

Acoustic leak detection systems in pressurized piping and boilers have been in use since the early 1970's. Sound waves are generated in three mediums: high-pressure fluid inside the pipes, 
the pipe walls, and the low-pressure fluid outside of the pipes. One technique for acoustic leak detection involves the installation of pressure transducers in the fluid and on the pipeline, which detect the continuous sound waves emanating from the turbulence created by the escaping gas. Detection ranges are not very high and may range from 10 to 120 feet. This depends on the noise level on the location of the pressure sensor. The optimum frequency range for structure borne leak detection sensors is $2-20 \mathrm{kHz}$ and for air borne signals the monitoring frequency range is $2-15 \mathrm{kHz}$.

\subsection{Past Research Done on Acoustic Leak Detection in Gas Pipelines}

Shack states that Lighthill was one of the first researchers to present a theoretical model for predicting the intensity of sound generated by a given flow. This model allowed him to develop a dimensional relationship for the noise generated by a subsonic turbulent jet where acoustic power is a function of density, velocity of the gas jet and the cross-sectional area of the jet. His equation predicts the acoustic power radiated by the jet in the audible frequency spectrum. Beginning May 1975 Applied Physics Laboratory (APL) started investigating the factors of importance in the operation of an acoustic leak detection system. Coupling of the sensor outside the pipeline makes it vulnerable to the ambient noise in the soil, however in case of a sensor placed inside the gaseous environment in the pipe it is less likely to detect soil borne noise because of the transmission losses through the pipe walls. APL found that a large improvement in the acoustic signal to noise ratio may be achieved by using active acoustic system through the use of correlation. Correlation of the signal used to excite the acoustic signal with the acoustic signal involves summing their product over a time interval $\mathrm{T}$, and then averaging the result. This gives higher signal to noise ratio for a longer integrating time. 
According to Parker active acoustic leak detection involves remote excitation of the gas contained within a buried pipeline network in the form of pressure oscillations that propagate throughout the system. This alternating gas pressure is coupled to the external soil medium either indirectly through radial displacement of the pipe walls in the case of an unperforated pipe or directly in case of a leak in the pipe. This type of coupling leads to the excitation of compressional and shear waves. An accelerometer type sensor may be used to detect the displacements occurring as a result of pressure oscillations. This involves the knowledge of such surface displacements.

Compressional waves arise as a result of pipe wall radial displacement, which causes the soil to be alternately compressed and expanded. Shear waves on the other hand are the results of two simultaneous effects. The couple established in the soil by the soil compression at an acoustic maximum and the expansion at the minimum causes the first effect. The second effect is due to the longitudinal displacement of the pipe walls along with radial expansion and contraction. Shear waves travel slower than compressional waves and the angle at which these waves approach the surface are different.

Parker found that the detection of holes in underground piping using an active acoustic approach couldn't simply rely on the measurement of the amplitude of surface displacement and there has to be some mechanism of rejecting false amplitude indications. He further found that the surface displacement directly above a $3 / 4$ inch diameter hole exceeds the average value of wall radiation by a factor of four. Since theoretically the amplitude of radiation from a leak varies as the cube of the radius this means that this wall radiation is same as from a half-inch diameter hole. This 
limits the leak detection capability of active acoustic leak detection system to detect large leaks only. However, it was experimentally confirmed that coupling of acoustic energy into an external leak path lead to great increase in the leak radiation compared to the wall radiation.

Sharp and Campbell note that the acoustical properties of tubular systems could be measured using pulse reflectometry, which enables the measurement of input impulse response of tubular systems. This involves the injection of a sound pulse into the object used in the study and recording the resulting reflections. Bore profile and input impedance of the object used could be obtained by analyzing sound pulse reflections. Sharp and Campbell in their study used a loudspeaker to send a sound pulse and then recorded the resulting reflections by a microphone installed on the outside of the tube. The input impulse response of the tubular object could be obtained by deconvolving these resulting reflections with the known input pulse, which could be done with the aid of Fourier analysis. Fourier transform of the impulse response gives the frequency response of the system.

Rajtar investigated acoustic emission signals as functions of the pipe pressure, the leak rate and the distance from the leak. He noted that the spectrum of the acoustic signal could be analyzed and compared to either a non-leaking background signal or experimentally determined leak "signature". In the first case poor correlation would indicate a leak while in the latter case a good correlation would indicate a leak. His lab experiments showed an increase in the leak signal above background signal with pipe pressure and the leak rate. Experiments performed in Rajtar's research involved measurements of leak signal spectrum as a function of distance for various 
leak rates. The leak signal could be picked up to a distance of 200 feet. Also the acoustic power of the detected signal increased with the increasing leak rate. Rajtar found that for a partially buried pipeline, signal is attenuated very strongly than pipelines that are above the surface.

Brodetsky and Savic present an approach where they place permanent monitoring units along the pipeline. These units detect acoustic signals in the pipeline and discriminate leak sounds from other man made or natural non-leak sounds. Their system involving these units can detect leaks as small as 1/32-inch diameter from a maximum distance of $600 \mathrm{~m}$ between two units. They emphasize on the fact that the monitoring units may pick up signals other than the leak signal and there has to be some mechanism to reject false leak type signals. These may be sounds of substances flowing through the pipeline, compressor and pump noises and external noises such as trains and cars. Their study involved an acoustic transmission line model, which is similar to an electric transmission line. This model replaced electric elements: $\mathrm{R}$ the resistance per unit length, $\mathrm{C}$ the capacitance per unit length, and $\mathrm{G}$ the leakage conductance per unit length with appropriate mechanical constants: Rm the damping due to friction per unit length, $M$ the mass per unit length, $\mathrm{Cm}$ the compliance per unit length, and $\mathrm{Gm}$ the loss at boundaries per unit length, respectively. They assume that a force is acting at one end of the transmission line and the other end of the line is loaded with mechanical impedance, this along with a propagation constant and particle velocity gives a relation for force at an element $\mathrm{dx}$ at a distance $\mathrm{x}$ from the loaded end. This force produced by a standard source at one end of the line can be measured with the aid of a piezo electric transducer. Unknown transmission line parameters like the propagation constant can be solved by the utilization of this information in the developed relation for force. 
The sound source used in this case was a steel ball 1 inch in diameter that was dropped on the pipeline form the height of 4 inches. This produced a sound impulse in the pipe that was measured at a number of points along the pipeline.

Bassim \& Tangri in their paper investigated the effect of material properties and wave propagation in pipelines on acoustic emission variables such as the root mean square (RMS) of the amplitude of the emitted signals. They also investigated the effect of other factors like geometry, shape and gas pressure within a leak. Their technique is based on the stress detection of waves that are emitted in a material when subjected to loads, which causes plastic deformation and/or crack initiation and propagation. According to Bassim \& Tangri two types of acoustic emissions, continuous and burst type, are generally observed during the deformation of these materials. Characterization of these signals put continuous type signal into low amplitude and high signal (less than few micro volts) density category, while the burst type signal comes in to high initial amplitude (few micro volts to few volts) signal category. They further say that continuous type signals may be produced during plastic straining (for example during tensile testing of unflawed steel specimens) whereas burst type signal may be generated during plastic zone deformation, crack initiation and crack growth (for example fracture tests on flawed specimens). The amplitude and frequency spectrum of the generated stress waves are also dependent on material characteristics such as microstructure and yield strength. Also the attenuation behavior of a material is sensitively dependent upon the frequency of the stress wave. Bassim \& Tangri carried out lab tests to determine the acoustic emission response during tensile and fracture tests on two pipeline steels and also to study the attenuation characteristics of steel pipes with and without a controlled leak. During the tensile test they found that low strength 
steel exhibits a low acoustic emission activity compared to the high strength steel. In case of fracture tests the acoustic emission was found to reach a maximum at the point of general yielding, which could detect plastic deformation that occurred before crack growth. . Attenuation tests suggested that the largest signal for all leak sizes was generated by the lowest frequency transducer.

Watanabe along with Matsukawa, Yukawa and Himmelblau describe a new method for detecting and locating a leak in a gas transport pipeline by an indirect acoustic method. They treat the pipeline as an acoustic tube and estimate the impulse response of the acoustic wave in the pipeline solely from the acoustic signal detected at two terminal sites in the pipeline. A test signal is used at the input site as an acoustic wave. A sudden leak in the pipeline causes a sharp impulse response to an acoustic wave that can be directly related to the site of the leak. They make some simplifying assumptions for successful implementation of the above stated acoustic method. These are as following

1. The test zone of the pipeline has two constrictions, one at the input and one at the output ends.

2. The test zone of the pipeline is a single pipe with no branches.

3. Only one leak occurs in the test zone.

4. The test zone of the pipeline has uniform cross-sectional area for its entire length.

5. The pressure at the input end of the test zone includes random fluctuations.

6. Pressure inside and near the constrictions in the test zone can be measured by detectors or microphones that have limited frequency bands.

7. Acoustic waves propagate in the pipeline without any attenuation and velocity of gas flow is negligible in comparison to the sound velocity. 
Assumption 1 was made to provide boundary conditions. Assumption 2 made sure that branched could not be regarded as leaks. Assumption 7 meant that the wall of the pipeline is thick and no acoustic energy passed through the wall. Theoretically they assumed a leak with circle hole at some distance between the input and center of the pipeline. A white noise was added at the input site to excite the acoustic signals, which were detected at the input and output sites by using microphones. With the aid of the wave equation and Fourier transform the information about the leak site could be determined. Watanabe and his co-researchers used discrete Fourier transform (DFT) instead of Fourier transform since the data were measured discretely. They also did an experimental analysis where they carried out experiments on the lab pipeline that seemed to validate their data theoretically with the only difference being the noise involved in the experiments.

Leis et al described the means to detect third party contacts with pipelines. The chains of events caused by an impact on a pipe usually are

1. Elastic waves, launched in the pipe wall which travels rapidly but then attenuates quickly.

2. Acoustic waves in the gas column that propagate long distances and get attenuated mainly due to classical absorption and wall loss mechanisms.

3. Stresses and strains caused by the acoustic wave as it propagate through the gas, which can then be detected by accelerometers mounted on the pipe.

They found the following characteristics to be common for any technique to be used successfully.

1. Uninterruptible power supply, 2. Sensors combined with related signal conditioning, processing and analysis, 3.Communication links, 4.Evaluation, response and control hierarchy. 
Min-Lee \& Jun-Lee (2000) carried out research to develop an acoustic emission technique for pipeline leak detection. They analyzed two different methods for determining source location; 1. reduction in signal amplitude with increasing distance from the source (attenuation based methods), and 2. increase in signal transit time with increasing distance from the source (time of flight based method). Lee's found that the characteristics of the signal generated by the turbulence of the gas in the pipeline is a wide band signal with less than $600 \mathrm{KHz}$ frequency. They noted that a leak in the pipeline generated acoustic waves, which propagates along the pipe wall. They also noted that there are typically two types of acoustic emission signals; burst and continuous signals. The leak signal is continuous signal and is measured as r.m.s voltage. They used four different types of sensors $150 \mathrm{KHz}, 225 \mathrm{KHz}, 500 \mathrm{KHz}$ and one broadband type. They compared the r.m.s value of the detected signals by these sensors with the corresponding signal stored in the computer memory. Leak was detected on the basis of the significant difference in the leak signal and the background signal.

\subsection{Signal and its Representation}

A signal may be defined as any physical quantity that varies with an independent variable or variables that may be space or time. When represented digitally signal is in its digital form. This is done by sampling and quantization of the signal. A signal may be represented by sinusoids. In its simplest form the amplitude of a sine or cosine wave A, its frequency $\mathrm{f}$, and phase $\varphi$ represent signal. For example $\mathrm{x}(\mathrm{t})=\mathrm{A} * \cos \left(2 * \mathrm{pi}^{*} \mathrm{f} * \mathrm{t}+\varphi\right)$. This information may also be converted to its complex form to be used in Fourier analysis. In Fourier analysis a signal can be decomposed into a set of sinusoids with different amplitudes, frequencies etc. In its complex form a signal may be 
of the form $x(t)=A * \exp (j * 2 * p i * f * t+\varphi)$. When a plot of frequency or phase is made with the amplitude the plot is called a spectrum.

\subsection{Signal Processing}

Signals may be classified as multi-channel and multidimensional; continuous time and discrete time; continuous valued and discrete valued; and deterministic and random signals. Signals may be processed by appropriate analog system, which is called analog signal processing or they may be processed digitally, which is called digital signal processing. Analog signal may be converted to a digital signal by using an analog to digital signal (A/D) converter and vice versa (Proakis, 1969). In today's world non-destructive evaluation (NDE) data is analyzed not only in the time and frequency domain but also in the amplitude domain, phase domain, cepstral domain, etc. to extract as much information from the signal as possible.

Sampling is the most important part of signal processing. This is basically the discretization of the analog signal or in other words selection of analog signals at discrete time instants. The time interval between the successive samples is called the sampling period and its inverse is called the sampling rate. According to Nyquist theory sampling rate should always be twice the highest frequency contained in the analog signal. Thus sampling changes a continuous time continuous value signal (which has a continuous value over continuous period of time) to discrete time continuous value signal. Quantization is done to change a signal from continuous value signal to discrete value signal. A discrete time signal and discrete value signal may be called a digital signal. 
Use of digital filters to improve the signal-to-noise ratio and time series modeling are some of the recent techniques used in acoustic methods of NDE. The feasibility of leak detection by acoustic emission technique depends on three factors:

1. Nature of acoustic emission radiated from the leak.

2. Attenuation between the leak and the sensor.

3. Background noise.

The physical origin of the leak signals is the fluctuating pressure filed associated with the turbulence in the fluid. The actual detection of the leak depends on the flow rate as this factor decides the energy content of the leak signal (Moorthy, 1992). The other alternative is intermittent monitoring and looking for a change in impedance of the pipeline. This will require an input of acoustic energy, such as speaker (Watanabe, 1992). The current generation of acoustic leak detection equipment uses two sensors (fixed to the exterior or interior of the pipeline) with the leak signal arriving form anywhere between these sensors. The leak signal received by both sensors is received at different times depending on their distance form the leak. The signals received by these sensors are transmitted to same processor and are cross-correlated. The cross-correlation output indicates the difference in transmission time of the signal from the leak to each sensor. The leak site can be located if the velocity of acoustic propagation in the pipeline is known. The pipe and its fittings either sides of a leak acts as cascade of filters that attenuates some frequencies in the leak signal while allowing others to propagate. If the filtering is quite different either side of a leak, acoustic correlation tends to fail. This can be remedied by equalization of the signals received at each sensor before cross correlation (Seaford, 1994). 


\section{Chapter 4}

\section{Gas Pipeline Instrumentation}

\subsection{WVU Source/Sink Flow Type Acoustic Signal Amplifier}

\section{Introduction}

Gas pipelines can only be easily accessed at line shut off valves, which are typically located at regular intervals about 60 kilometers apart. At these line shut-off valves there is usually available above ground $1 / 2$ inch NPT access port above a shut-off valve. Thus to obtain acoustic signals from the gas inside the pipeline, the required instrumentation is best installed on the access ports. A weak rarefaction wave is emitted following the occurrence of a leak. It may take a long time before equilibrium pressure is re-established. During that time the low frequency and low $\Delta \mathrm{P}$ waves are difficult to detect inside a high pressure pipeline filled with high frequency flow noise, which is only detectable with a microphone. Therefore a large 3-inch diameter diaphragm was installed in an attempt to detect the low frequency waves associated with a leak. This diaphragm serves as a pressure signal amplifier with either source or sink flow. It was included in the $1^{\text {st }}$ generation WVU instrumentation package that was designed to mount on a $1 / 2$ inch NPT access port. As with flow in a venturi, 2-D source or sink flow amplifies the flow velocity by its area change. The advantage of aerodynamic amplification is that it also serves as a filter as it amplifies only ramp type signals and not random noise.

\section{Experimental Setup}

All instruments were mounted inside a high-pressure housing connected to the pipeline by means of a $1 / 2$ inch pipe. The instrumentation involved an acoustic step function signal amplifier, a 
microphone made from a phonograph cartridge, a line pressure transducer, a thermocouple and an externally mounted accelerometer. The acoustic step function amplifier consists of flow leading form a $1 / 2$ inch pipe to two parallel and closely spaced discs to create source/sink flow. The deflection of a 0.005 -inch thick and 3 inch diameter phosphor bronze diaphragm was measured relative to a rigid 1/8 -inch thick and 3-inch diameter brass plate. Strain gauges of 5 $\mathrm{mm}$ in length, $350 \mathrm{ohms}$ in resistance were used to measure diaphragm deflection. Two needle valves were installed, one to bring the instrument slowly up to the pipeline pressure, and the other to relieve pressure inside the housing. An accelerometer was mounted on the outside of the high-pressure housing. 300-psi steel flanges were used to provide access to the instrumentation inside the high-pressure housing (see figure 4.4). A 6-volt battery was installed outside of the housing to power the strain gage.

The brass plate (see figure 4.1) was held in place by three flat head $1 / 4 \mathrm{NC}$ thread, screws. These screws were soldered to a galvanized ring. A strain gage was used to measure the displacement of the diaphragm. The source/sink-mounting ring had four $1 / 2$ inch diameter holes to assure pressure equalization to the upper side of the diaphragm. Three of these holes were also needed to provide access to the nuts used for adjustment of the diaphragm gap width.

\subsection{Principle of Operation}

A leak in a pipeline generates a pressure step or ramp function, which results in a relatively long duration $\mathrm{dp} / \mathrm{dt}$ pipeline pressure signal. When a leak occurs the pressure in the pipeline drops by $\Delta \mathrm{P}$ in a step or ramp type fashion, which results in a temporary outflow from the high pressure housing back into the pipeline. Since the flow so induced is of low velocity and short duration, 
the associated $\Delta \mathrm{P}$ should be amplified. The change in pressure $\Delta \mathrm{P}$ is amplified by guiding the induced flow through both a $1 / 2$ inch pipe nipple and in between a 3-inch diameter brass plate and 3-inch diameter phosphor bronze diaphragm. This produces two dimensional radial source or sink flow. Decreasing flow area with radial sink type inflow increases the velocity and lowers the static pressure in the interior region of the space between the two discs. For any given source type outflow rate, the radial outflow pressure recovery, lowers in the interior region of the space between the two discs. The resulting suction force in the interior part of the diaphragm tends to narrow the airflow gap, that phenomenon further adds to the amplification rate. Either the radial sink type inflow (fig 4.2) or source type outflow (fig 4.1) between the two three inch diameter discs increases the velocity in the interior region. This results in a suction force, which is similar to that occurring in the throat of a venturi. Without the disc the force will be limited to the momentum of flow in the $1 / 2$ inch pipe nipple $\left(\pi r_{o}^{2} \rho V_{o}^{2}\right)$. The suction force hereby created inside the gap, deflects the diaphragm to narrow the gap. The acoustic signal amplification $\left(\mathrm{A}_{\mathrm{amp}}\right)$ is the ratio of this suction force to the momentum of the flow inside the $1 / 2$ inch diameter pipe nipple with velocity Vo. Source sink flow signal amplification is obtained when diaphragm suction force more than doubles the momentum of the flow inside the $\frac{1}{2} 2$ inch pipe nipple.

Two configurations have been designed and built to measure the disc deflection due to the suction force from an acoustic signal generated in an in or outflow.

A. A restrained diaphragm was soldered along its perimeter to a rigid ring. This restricted the diaphragm deflection at the inner portion. This resulted in a very low strain gage signal. 
B. Diaphragm resting on a ring at its perimeter and held in place by three thin $1 / 2$ inch wide strain gage beams. This provided a much stronger signal.

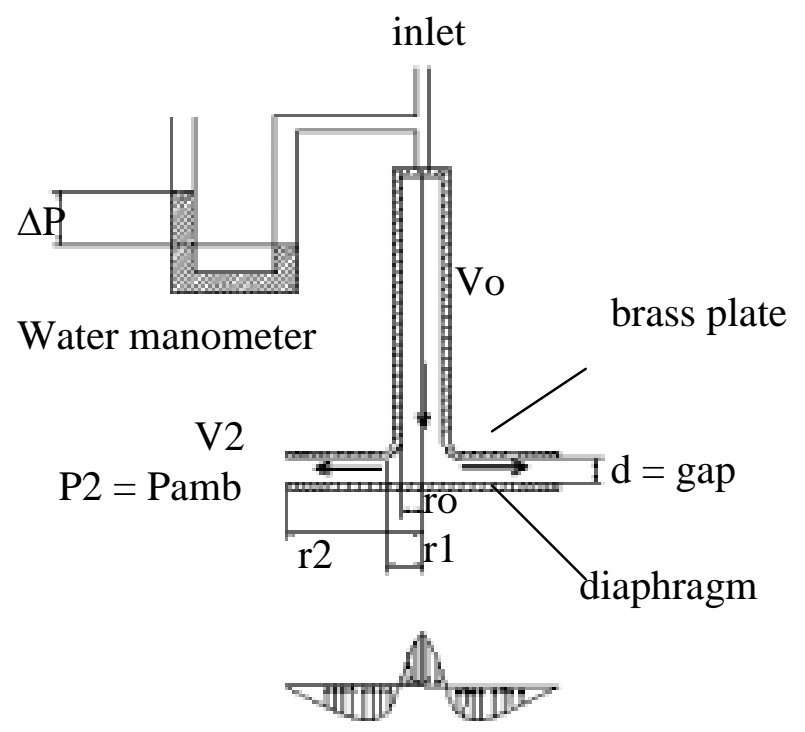

Fig 4.1: Figure Showing Source Flow Entering through a $1 \frac{1}{2}$ Inch Port into a Gap between Two Flat Plates.
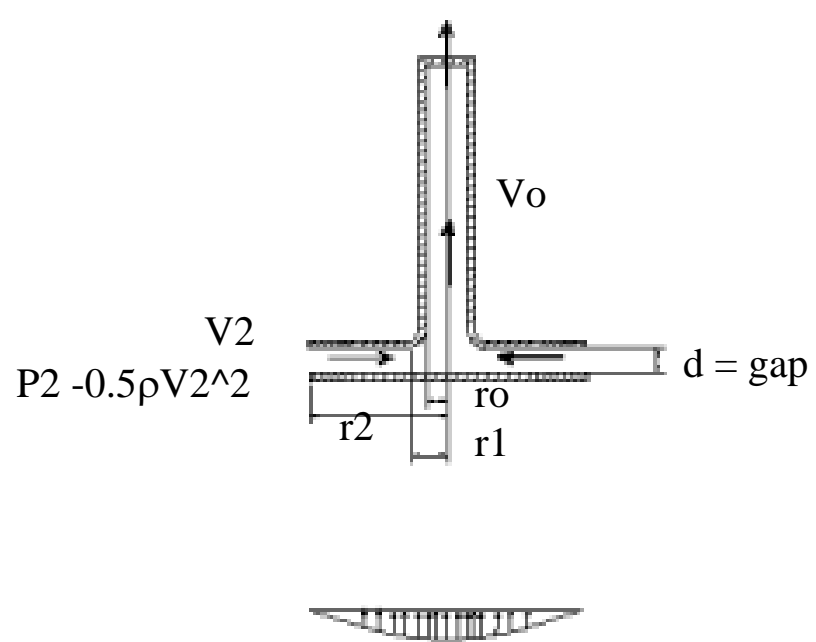

Fig 4.2: Figure Showing Sink Flow Leaving through the Top of the $1 / 2$ Inch Pipe Nipple. 


\subsection{Ideal Friction Free Flow Source/Sink Acoustic Signal Amplification}

After the housing is pressurized the acoustic step signals associated with a leak induce either inflow or outflow through the $1 / 2$ inch diameter pipe. The flow accelerates inside the gap formed by the 0.005 -inch thick phosphor bronze diaphragm, with either radial in or outflow. Sink flow enters at the diaphragm radius $r_{2}=39 \mathrm{~mm}$ and exits from the nipple at radius $r_{o}=6.5 \mathrm{~mm}$. The symbol (d) represents the gap between the flat brass plate and the diaphragm. Locations 1 and 2 are indicated by $r_{1}=11 \mathrm{~mm}$ and $r_{2}=39 \mathrm{~mm}$ (see fig 4.1 )

The minimum flow area and thus highest velocity across at $A_{1}=2 \pi r_{1} d$

Source flow exit area is given by $A_{2}=2 \pi r_{2} d$

Flow area of the $1 / 2$ inch nipple is given by $A_{o}=\pi r_{o}{ }^{2}$

Applying continuity $\rho \mathrm{AV}=$ constant

gives, $A_{2} V_{2}=A_{1} V_{1}$

or $2 \pi r_{2} V_{2} d=2 \pi r_{1} V_{1} d$

This sets the velocity ratio as a function of radius ratio $\frac{V_{2}}{V_{1}}=\frac{r_{1}}{r_{2}}$

Or $V_{2}=V_{1} \frac{r_{1}}{r_{2}}$

Similarly $A_{2} * V_{2}=A_{o} * V_{o}$

$\frac{V_{2}}{V_{0}}=\frac{\pi * r_{o}{ }^{2}}{2 * \pi * r_{2} * d}=\frac{6.5^{2}}{2 * 39 * d}=\frac{0.542}{d}$ where $\mathrm{d}$ is in $\mathrm{mm}$

At any radius $r$

$A_{r} * V_{r}=A_{o} * V_{0} \quad$ or $\quad V_{r} * 2 * \pi * r * d=V_{o} * \pi * r_{o}^{2} \quad$ or $\quad V_{r}=V_{o} \frac{r_{o}^{2}}{2 * r * d}$

In equation (4.5) the gap $d$ is in $m m$ and $V_{r}$ is the radial velocity at any radius $r$ in equation (4.6) 


\section{Force Amplification}

The suction force $F_{s}$ on the diaphragm is the integral of the $\Delta \mathrm{P}$ pressure forces from $r=r 1$ to $r_{2}$. Assuming friction free flow has constant total pressure with Bernoulli equation gives for source flow only

$P+\frac{1}{2} \rho V_{r}^{2}=P_{\text {amb }}+\frac{1}{2} \rho V_{2}^{2}=P_{\text {total }}$

or $\Delta P=\frac{1}{2}\left(\rho V_{r}^{2}-\rho V_{2}^{2}\right)$ where $V_{r}=\frac{V_{2} r_{2}}{r}$

$F_{s}=\int_{r_{1}}^{r_{2}} \Delta P 2 \pi r d r$

$F_{s}=\int_{r_{1}}^{r_{2}} \frac{1}{2}\left(\rho V_{r}^{2}-\rho V_{2}^{2}\right) 2 \pi r d r$

Combining equations 4.6 and 4.8 gives

$F_{s}=\frac{1}{2} \rho V_{2}^{2} \pi r_{2}^{2} \int_{r_{1}}^{r_{2}}\left[\left(\frac{V_{r}}{V_{2}}\right)^{2} \frac{2 r d r}{r_{2}^{2}}-\frac{2 r d r}{r_{2}^{2}}\right]$

integration gives $F_{s}=\rho \frac{1}{2} V_{2}^{2} \pi r_{2}^{2}\left[2 \ln \frac{r_{2}}{r_{1}}-1+\frac{r_{1}^{2}}{r_{2}^{2}}\right]$

As the source flow exits the $1 / 2$ inch pipe nipple, assume it stagnates to pressure $P_{\text {total }}$ and then creates a positive pressure on the diaphragm from $r=0$ to $r 1$ of magnitude $\mathrm{P}_{\text {total- }} \mathrm{P}_{\mathrm{amb}}=$ $\frac{1}{2} \rho V_{2}^{2}$ from equation 4.7, which creates a force $F_{o}=\frac{1}{2} \rho V_{2}^{2} \pi r_{0}^{2}$ and the Friction Free Flow Diaphragm Amplification Factor $A_{\text {amp }}=\frac{F_{s}-F_{o}}{F_{s}}=\frac{r_{2}^{2}}{r_{1}{ }^{2}}\left[2 \ln \frac{r_{2}}{r_{1}}-1+\frac{r_{1}^{2}}{r_{2}^{2}}\right]$ $A_{\text {amp }}=\left(\frac{39}{11}\right)^{2}\left[2 \ln \frac{39}{11}-1+\left(\frac{39}{11}\right)^{2}\right]=19$ 


\section{Air Properties}

$\mathrm{P}=1 \mathrm{Mpa}=145 \mathrm{psia}$

$\mathrm{T}=27{ }^{0} \mathrm{C}=300{ }^{0} \mathrm{~K}$

$\mathrm{R}=8314 / 28.97=0.287 \mathrm{~kJ} / \mathrm{kgK}$

$\mathrm{k}=1.4$

$\mathrm{v}_{\text {air }}=\mathrm{RT} / \mathrm{P}=(0.287 * 300 * 1000 / 101325)=0.84974 \mathrm{~m}^{3} / \mathrm{kg}$ at 1 atmosphere

$\rho=\mathrm{P} / \mathrm{RT}$

$\rho=\frac{1000000}{0.287 * 300 * 1000}=11.6144 \mathrm{~kg} / \mathrm{m}^{3}$ at 9.86 atm or 145 psia

\section{Natural Gas properties}

$\mathrm{P}=300 \mathrm{psia}=2.71 \mathrm{MPa}$

$\mathrm{T}=25^{0} \mathrm{C}=298^{0} \mathrm{~K}$

$\mathrm{R}=8314 / 16=0.5182 \mathrm{~kJ} / \mathrm{kgK}$

$\mathrm{K}=1.299$

$\mathrm{V}_{\text {methane }}=\mathrm{RT} / \mathrm{P}=(0.5182 * 298 * 1000 / 101325)=1.5058 \mathrm{~m}^{3} / \mathrm{kg}$ at 1 atmosphere

$\rho=\mathrm{P} / \mathrm{RT}$

$\rho=\frac{2.17 * 10^{6}}{0.5182 * 298 * 1000}=14.05 \mathrm{~kg} / \mathrm{m}^{3}$ at $20.4 \mathrm{~atm}$ or $300 \mathrm{psia}$

\subsection{Force Calculations from $\mathrm{dP} / \mathrm{dt}$ pressure signals}

Momentum force in the $1 / 2$ inch pipe $=\operatorname{mdot}^{*} V_{o}=\rho A_{o} V_{o}^{2}=\rho \pi r_{0}^{2} V_{o}^{2}$

Volume of the gas pipeline housing, $\mathrm{Vol}=0.0013 \mathrm{~m}^{3}$

Since $\mathrm{dB}=20 \log \frac{P}{P_{r e f}}$

Thus at $\mathrm{P}=\mathrm{P}_{\text {ref }}$ the sound pressure level corresponds to $0 \mathrm{~dB}$ 
Also $\mathrm{P}=20 * 10^{-6} * 10^{(\mathrm{dB} / 20)}$

Dynamic pressure $\Delta \mathrm{P}=\frac{1}{2} \rho V^{2}$ or $\mathrm{V}=\sqrt{\frac{2 \Delta \mathrm{P}}{\rho}}=\sqrt{\frac{2 * 20 * 10^{-6} * 10^{\frac{d B}{20}}}{\rho}}$

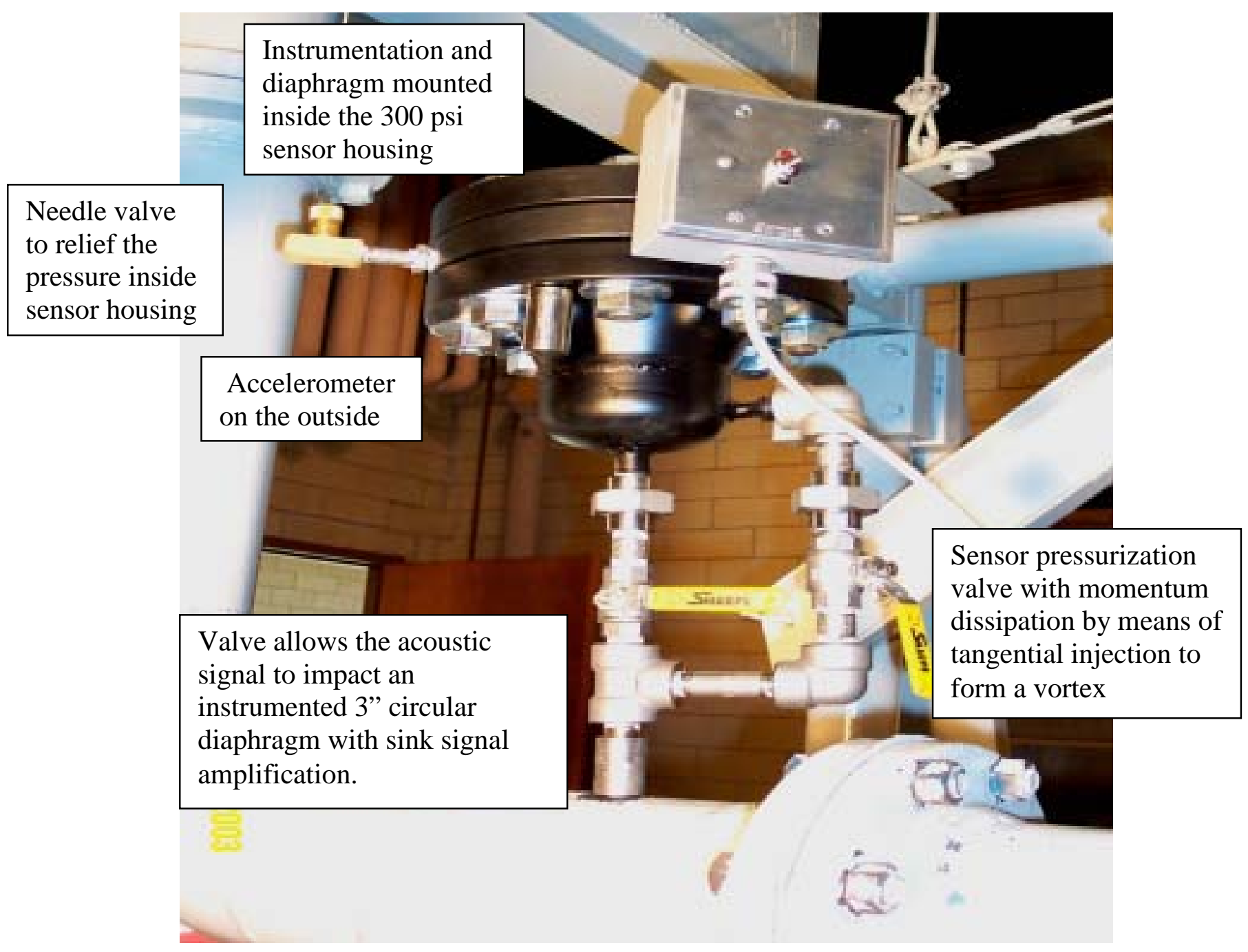

Fig 4.3: Picture of the source/sink flow acoustic signal amplifier housing.

Now ideal gas relation gives $P=\frac{m R T}{V o l}$ differentiating with time gives $\frac{\mathrm{dP}}{d t}=\frac{d m}{d t} \frac{R T}{V o l}$ also $\frac{\mathrm{dm}}{d t}=m d o t=-\rho A_{0} V_{0}$ 
which gives $\frac{\mathrm{dP}}{d t}=-\rho A_{o} V_{o} \frac{R T}{V o l}$

Flow velocity in the $1 / 2$ inch diameter pipe is then given by $V_{o}=-\frac{d P}{d t} \frac{V o l}{A_{o}} \frac{1}{P}$ where $P=\rho R T$ net force on the diaphragm is given by $F_{s}=A_{\text {amp }} F_{o}, F_{o}$ can be obtained using $4.9 \& 4.15$ Thus for a gap of $1 \mathrm{~mm}$ Amplification $A_{\text {amp }}=19$

In Tables $4.1 \& 4.2$ various relations have been developed from ramp signal in $\mathrm{dB} / \mathrm{sec}$. These are the ramp signal in $\mathrm{Pa} / \mathrm{sec}$, outflow velocity in the $1 / 2$ inch nipple in $\mathrm{m} / \mathrm{sec}$, momentum Fo in the $1 / 2$ inch nipple in $\mathrm{N}$ and gram weight, net force on the diaphragm Fs in $\mathrm{N}$ and gram weight, airflow rate at the respective pressure in $\mathrm{cc} / \mathrm{sec}$, airflow rate at 1 atmosphere in $\mathrm{cc} / \mathrm{sec}$, force on the diaphragm at $1 \mathrm{~mm}$ spacing between the diaphragm and the brass plate in $\mathrm{N}$ and gram weight.

The ramp signal in $\mathrm{dB} / \mathrm{s}$ is used from $70 \mathrm{~dB} / \mathrm{s}$ to $150 \mathrm{~dB} / \mathrm{s}$ in increments of $10 \mathrm{~dB} / \mathrm{s}$. Using the relation $\mathrm{dB}=20 \log \frac{P}{P_{\text {ref }}}$ where $\mathrm{P}$ and $\mathrm{P}_{\text {ref }}$ are in Pascal or $\mathrm{dB} / \mathrm{s}=20 \log \frac{P}{P_{\text {ref }}}$ where $\mathrm{P}$ and $\mathrm{P}_{\text {ref }}$ are in Pascal/s, dP/dt is derived in Pascal /s from dB/s. Further the outlet velocity in the $1 / 2$ inch nipple is obtained for various $\mathrm{dB} / \mathrm{s}$ in $\mathrm{m} / \mathrm{s}$. Since the momentum in the $1 / 2$ inch nipple is equal to mdot $* \mathrm{~V}_{\mathrm{o}}=\rho \mathrm{A}_{\mathrm{o}} \mathrm{V}_{\mathrm{o}}^{2}=\rho \pi \mathrm{r}_{0}^{2} \mathrm{~V}_{\mathrm{o}}^{2}$, momentum force in the $1 / 2$ inch nipple is obtained using the velocity in calculated above. Also since $\mathrm{V} 2 / \mathrm{Vo}=0.542 / \mathrm{gap}, \mathrm{V} 2=\mathrm{Vo}$ at a gap equal to 0.542 $\mathrm{mm}$. This sets the force Fs equal to $64 *$ Fo which is maximum amplification rate times the momentum force in the $1 / 2$ inch nipple. This force can be obtained in gram weight by multiplying the force in Newton by 1000/9.8. The airflow rate is obtained in cc/s at pressure 10 atmosphere by using the relation $\mathrm{AoV}$ o for various $\mathrm{dB} / \mathrm{s}$.

The force on the diaphragm in $\mathrm{N}$ at a gap of $1 \mathrm{~mm}$ is given by equations 4.5 and 4.8.This force 
is also calculated in gram weights. The corresponding graphs are shown in the figures 4.5 to 4.12 and figures 4.14 to 4.21 .

\begin{tabular}{|c|c|c|c|c|c|c|}
\hline $\begin{array}{l}\text { Ramp } \\
\text { Signal } \\
\text { (dB/s) } \\
\end{array}$ & $\begin{array}{l}\text { Ramp } \\
\text { Signal } \\
(\mathrm{Pa} / \mathrm{s}) \\
\end{array}$ & $\begin{array}{l}\text { Outflow } \\
\text { Velocity } \\
(\mathrm{m} / \mathrm{s})\end{array}$ & $\begin{array}{l}\text { Momentum } \\
\text { Force } \\
\text { (N) }\end{array}$ & $\begin{array}{l}\text { Momentum } \\
\text { Force } \\
\text { (gram wt.) }\end{array}$ & $\begin{array}{l}\text { Force at } \\
\text { V2 = Vo } \\
(\mathrm{N})\end{array}$ & $\begin{array}{l}\text { Force at } \\
\text { V2 = Vo } \\
\text { (gram wt.) }\end{array}$ \\
\hline 70 & 0.063245553 & 6.32456E-07 & $6.1633 \mathrm{E}-16$ & $6.28267 \mathrm{E}-14$ & $4.06778 \mathrm{E}-14$ & 4.15079E-12 \\
\hline 80 & 0.2 & 0.000002 & $6.1633 \mathrm{E}-15$ & $6.28267 \mathrm{E}-13$ & 4.06778E-13 & 4.15079E-11 \\
\hline 90 & 0.632455532 & 6.32456E-06 & $6.1633 \mathrm{E}-14$ & $6.28267 \mathrm{E}-12$ & $4.06778 \mathrm{E}-12$ & 4.15079E-10 \\
\hline 100 & 2 & 0.00002 & $6.1633 \mathrm{E}-13$ & 6.28267E-11 & $4.06778 \mathrm{E}-11$ & 4.15079E-09 \\
\hline 110 & 6.32455532 & 6.32456E-05 & $6.1633 \mathrm{E}-12$ & $6.28267 \mathrm{E}-10$ & $4.06778 \mathrm{E}-10$ & 4.15079E-08 \\
\hline 120 & 20 & 0.0002 & $6.1633 \mathrm{E}-11$ & 6.28267E-09 & 4.06778E-09 & 4.15079E-07 \\
\hline 130 & 63.2455532 & 0.000632456 & $6.1633 \mathrm{E}-10$ & 6.28267E-08 & 4.06778E-08 & 4.15079E-06 \\
\hline 140 & 200 & 0.002 & 6.1633E-09 & 6.28267E-07 & 4.06778E-07 & 4.15079E-05 \\
\hline 150 & 632.455532 & 0.006324555 & $6.1633 \mathrm{E}-08$ & 6.28267E-06 & 4.06778E-06 & 0.000415079 \\
\hline
\end{tabular}

Table 4.1: Table Showing Behavior of Outflow Velocity and Force at Different Gaps with Stagnation Pressure in an Air Filled Line.

\begin{tabular}{|c|c|}
\hline Gap d & Amplification \\
\hline \multicolumn{2}{|l|}{$(\mathrm{mm})$} \\
\hline 0.542 & 64.68 \\
\hline 0.6 & 52.78 \\
\hline 0.8 & 29.69 \\
\hline 1 & 19.00 \\
\hline 1.2 & 13.19 \\
\hline 1.4 & 9.69 \\
\hline 1.6 & 7.42 \\
\hline 1.8 & 5.86 \\
\hline 1.9 & 5.26 \\
\hline
\end{tabular}

Table 4.2: Amplification Aamp as a Function of Gap d. 


\begin{tabular}{|c|c|c|c|c|}
\hline $\begin{array}{l}\text { Ramp } \\
\text { Signal } \\
\text { (dB/s) }\end{array}$ & $\begin{array}{l}\text { Ramp } \\
\text { Signal } \\
(\mathrm{Pa} / \mathrm{s})\end{array}$ & $\begin{array}{l}\text { Air flow rate } \\
\text { (cc) }\end{array}$ & $\begin{array}{l}\text { Force at gap } \\
\text { equal } 1 \mathrm{~mm} \\
(\mathrm{~N})\end{array}$ & $\begin{array}{l}\text { Force at gap } \\
\text { equal } 1 \mathrm{~mm} \\
\text { (Gram wt.) }\end{array}$ \\
\hline 70 & 0.063245553 & 8.39047E-05 & 1.17103E-14 & 1.19493E-12 \\
\hline 80 & 0.2 & 0.00026533 & 1.17103E-13 & 1.19493E-11 \\
\hline 90 & 0.632455532 & 0.000839047 & 1.17103E-12 & 1.19493E-10 \\
\hline 100 & 2 & 0.0026533 & 1.17103E-11 & 1.19493E-09 \\
\hline 110 & 6.32455532 & 0.008390471 & 1.17103E-10 & 1.19493E-08 \\
\hline 120 & 20 & 0.026533 & 1.17103E-09 & 1.19493E-07 \\
\hline 130 & 63.2455532 & 0.083904713 & 1.17103E-08 & 1.19493E-06 \\
\hline 140 & 200 & 0.26533 & 1.17103E-07 & 1.19493E-05 \\
\hline 150 & 632.455532 & 0.839047132 & 1.17103E-06 & 0.000119493 \\
\hline
\end{tabular}

Table 4.3: Table Showing Behavior of Air Flow Rate and Force at Gap Equal $1 \mathrm{~mm}$ with Stagnation Pressure in an Air Filled Line.

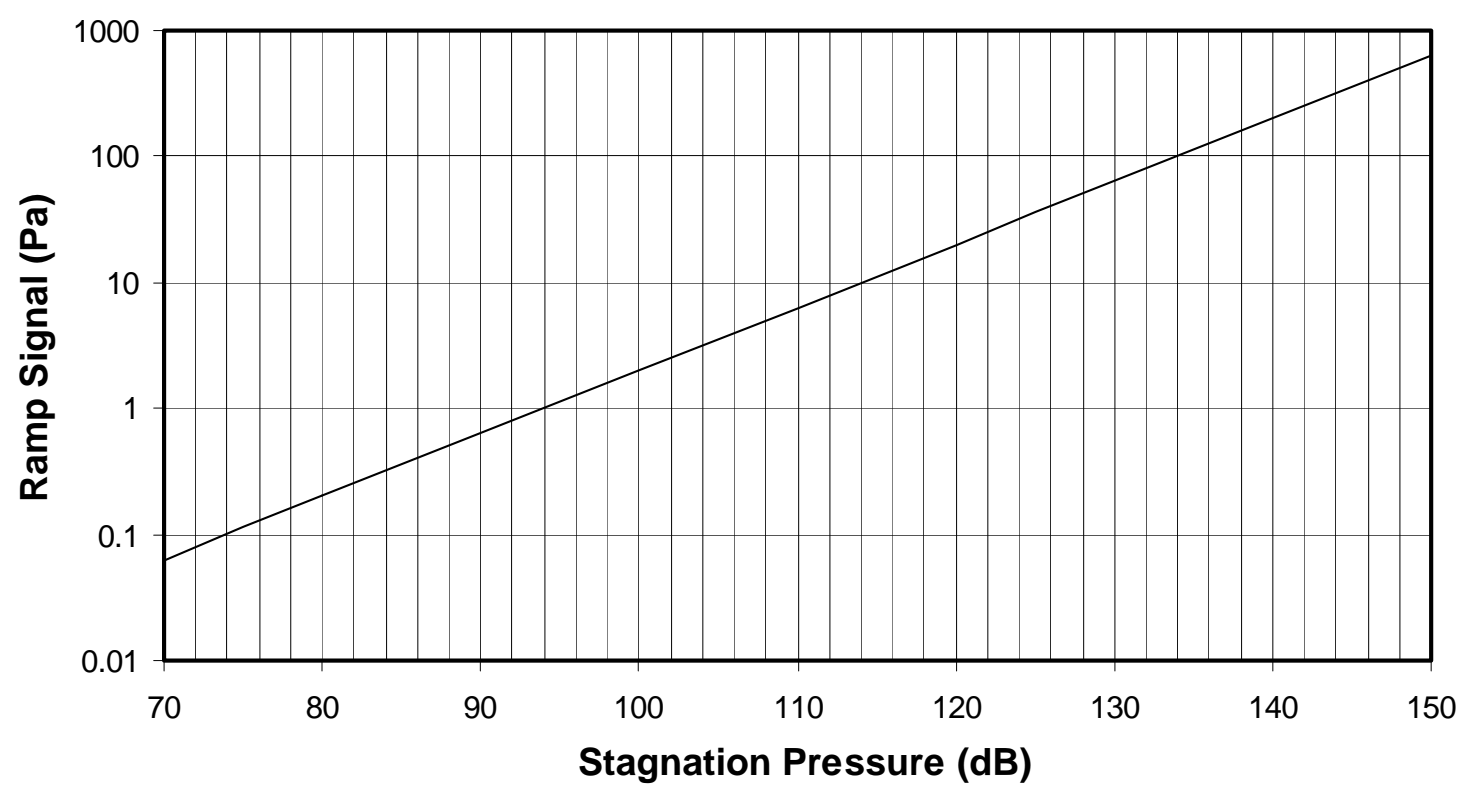

Fig 4.4: Stagnation Pressure in Pascal as a Function of Stagnation Pressure in $\mathrm{dB}$. 


\begin{tabular}{|c|c|c|c|c|c|c|}
\hline $\begin{array}{l}\text { Ramp } \\
\text { Signal } \\
(\mathrm{dB} / \mathrm{s})\end{array}$ & $\begin{array}{l}\text { Ramp } \\
\text { Signal } \\
(\mathrm{Pa} / \mathrm{s})\end{array}$ & $\begin{array}{l}\text { Outflow } \\
\text { velocity } \\
(\mathrm{m} / \mathrm{s})\end{array}$ & $\begin{array}{l}\text { Momentum } \\
\text { Force } \\
\text { (N) }\end{array}$ & $\begin{array}{l}\text { Momentum } \\
\text { Force } \\
\text { (Gram wt.) }\end{array}$ & $\begin{array}{l}\text { Force at } \\
\text { V2 = Vo } \\
\text { (N) }\end{array}$ & $\begin{array}{l}\text { Force at } \\
\text { V2 = Vo } \\
\text { (Gram wt.) }\end{array}$ \\
\hline 80 & 0.2 & 7.38007E-07 & $1.01521 \mathrm{E}-15$ & $1.03487 \mathrm{E}-13$ & $6.70036 \mathrm{E}-14$ & $6.8371 \mathrm{E}-12$ \\
\hline 90 & 0.632455532 & 2.33378E-06 & $1.01521 \mathrm{E}-14$ & $1.03487 \mathrm{E}-12$ & $6.70036 \mathrm{E}-13$ & $6.8371 \mathrm{E}-11$ \\
\hline 100 & 2 & 7.38007E-06 & $1.01521 \mathrm{E}-13$ & $1.03487 \mathrm{E}-11$ & $6.70036 \mathrm{E}-12$ & $6.8371 \mathrm{E}-10$ \\
\hline 110 & 6.32455532 & 2.33378E-05 & $1.01521 \mathrm{E}-12$ & $1.03487 \mathrm{E}-10$ & $6.70036 \mathrm{E}-11$ & $6.8371 \mathrm{E}-09$ \\
\hline 120 & 20 & 7.38007E-05 & $1.01521 \mathrm{E}-11$ & 1.03487E-09 & $6.70036 \mathrm{E}-10$ & $6.8371 \mathrm{E}-08$ \\
\hline 130 & 63.2455532 & 0.000233378 & $1.01521 \mathrm{E}-10$ & 1.03487E-08 & 6.70036E-09 & $6.8371 \mathrm{E}-07$ \\
\hline 140 & 200 & 0.000738007 & $1.01521 \mathrm{E}-09$ & $1.03487 \mathrm{E}-07$ & 6.70036E-08 & $6.8371 \mathrm{E}-06$ \\
\hline 150 & 632.455532 & 0.002333784 & $1.01521 \mathrm{E}-08$ & 1.03487E-06 & 6.70036E-07 & $6.8371 \mathrm{E}-05$ \\
\hline
\end{tabular}

Table 4.4: Table Showing Behavior of Outflow Velocity and Various Forces with Stagnation Pressure in Methane Filled Line.

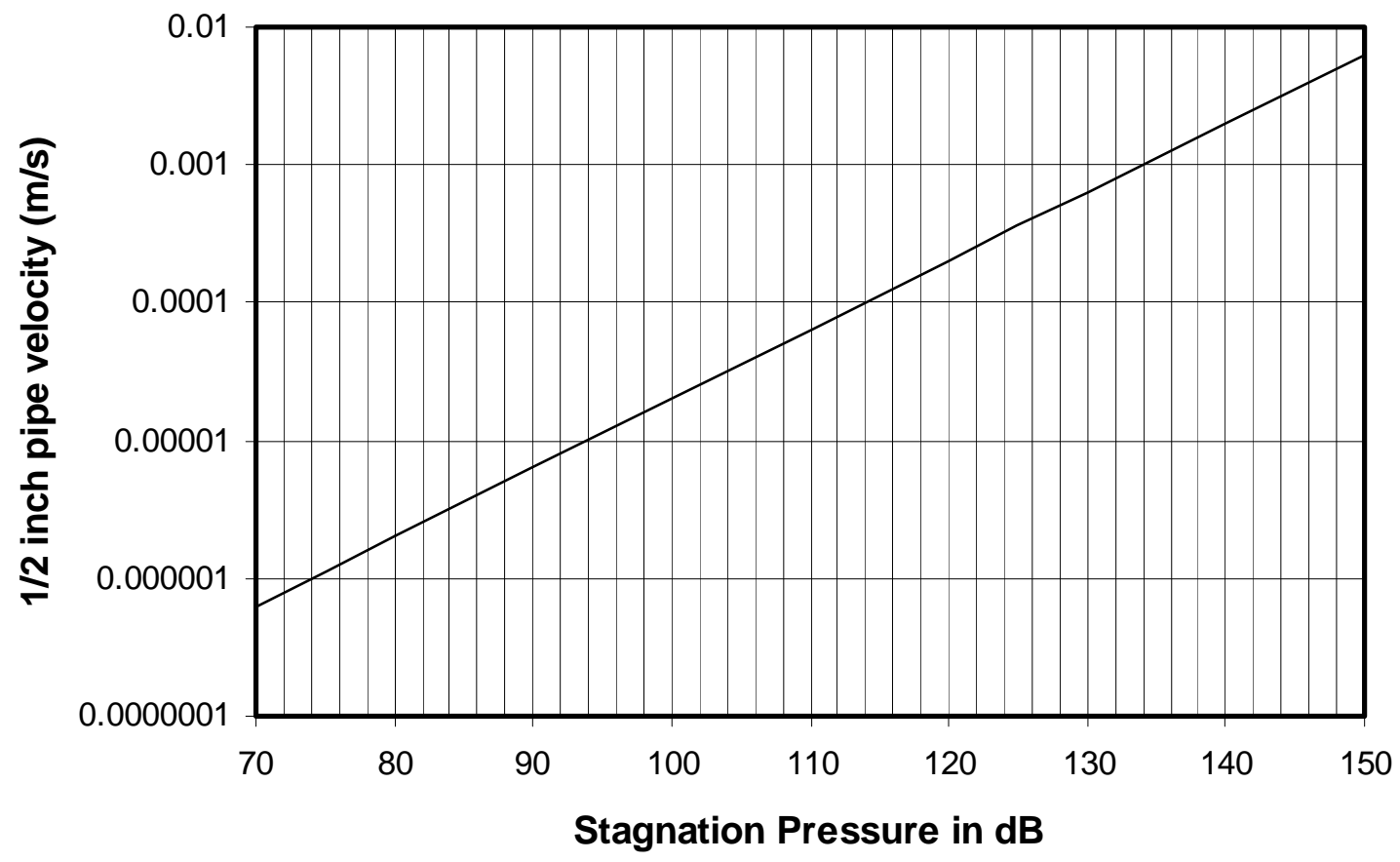

Fig 4.5: 1/2 inch Pipe Velocity Vo as a Function of Stagnation Pressure in $\mathrm{dB}$. 


\begin{tabular}{|c|c|c|c|c|}
\hline $\begin{array}{l}\text { Ramp } \\
\text { Signal } \\
(\mathrm{dB} / \mathrm{s})\end{array}$ & $\begin{array}{l}\text { Ramp } \\
\text { Signal } \\
(\mathrm{Pa} / \mathrm{s})\end{array}$ & Air flow rate & $\begin{array}{l}\text { Force at gap } \\
\text { equal } 1 \mathrm{~mm} \\
(\mathrm{~N})\end{array}$ & $\begin{array}{l}\text { Force at gap } \\
\text { equal } 1 \mathrm{~mm} \\
\text { (Gram wt.) }\end{array}$ \\
\hline 70 & 0.063245553 & 3.09611E-05 & $1.92889 \mathrm{E}-15$ & $1.96826 \mathrm{E}-13$ \\
\hline 80 & 0.2 & $9.79077 \mathrm{E}-05$ & $1.92889 \mathrm{E}-14$ & $1.96826 \mathrm{E}-12$ \\
\hline 90 & 0.632455532 & 0.000309611 & $1.92889 \mathrm{E}-13$ & $1.96826 \mathrm{E}-11$ \\
\hline 100 & 2 & 0.000979077 & 1.92889E-12 & $1.96826 \mathrm{E}-10$ \\
\hline 110 & 6.32455532 & 0.003096115 & 1.92889E-11 & 1.96826E-09 \\
\hline 120 & 20 & 0.009790775 & $1.92889 \mathrm{E}-10$ & 1.96826E-08 \\
\hline 130 & 63.2455532 & 0.030961149 & 1.92889E-09 & 1.96826E-07 \\
\hline 140 & 200 & 0.097907749 & 1.92889E-08 & $1.96826 \mathrm{E}-06$ \\
\hline 150 & 632.455532 & 0.309611488 & 1.92889E-07 & 1.96826E-05 \\
\hline
\end{tabular}

Table 4.5: Table Showing Behavior of Air Flow Rate and Force with Stagnation Pressure in Methane Filled Line.

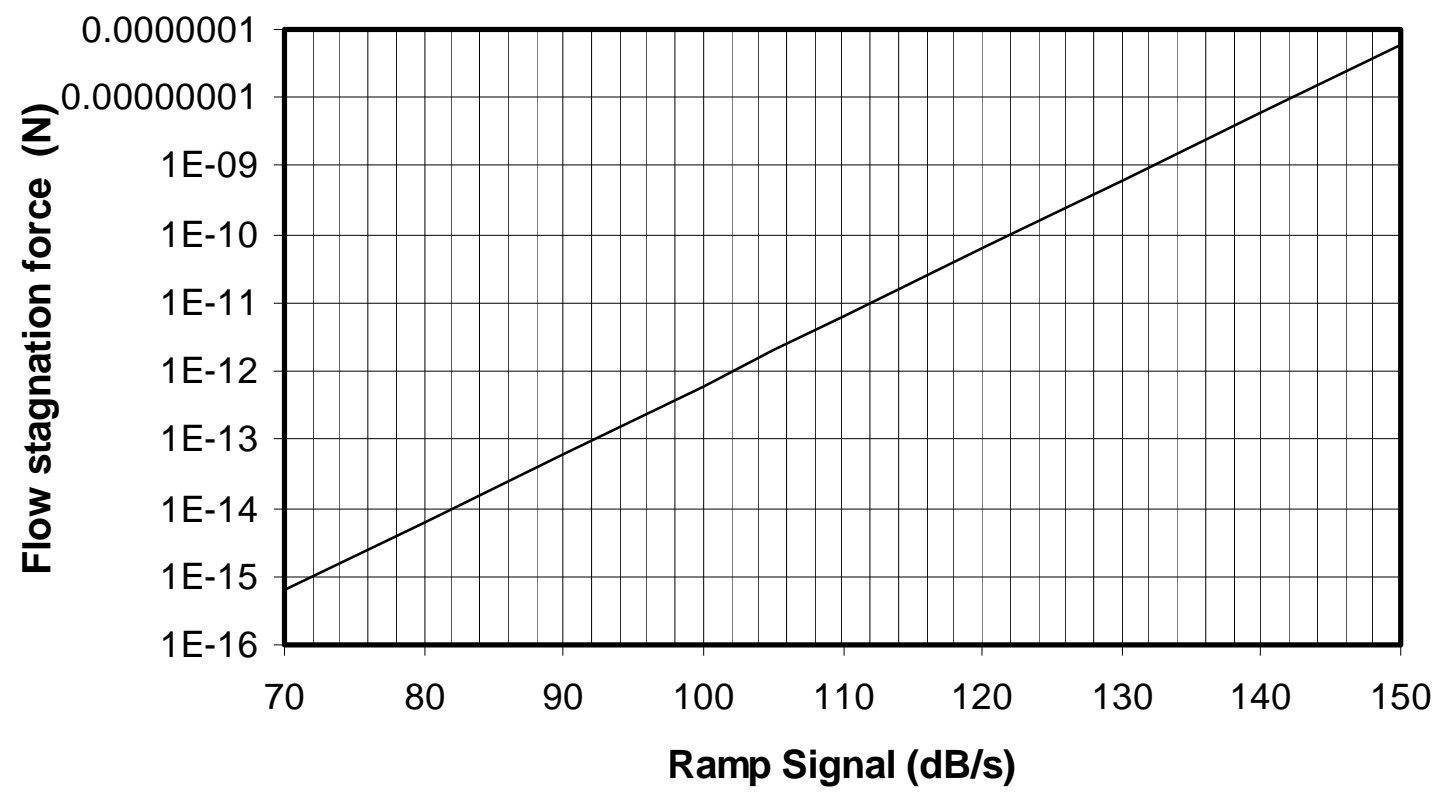

Fig 4.6: Flow Stagnation Force in $1 / 2$ inch Pipe as a Function of Stagnation Pressure in dB for an Air Filled Line. 


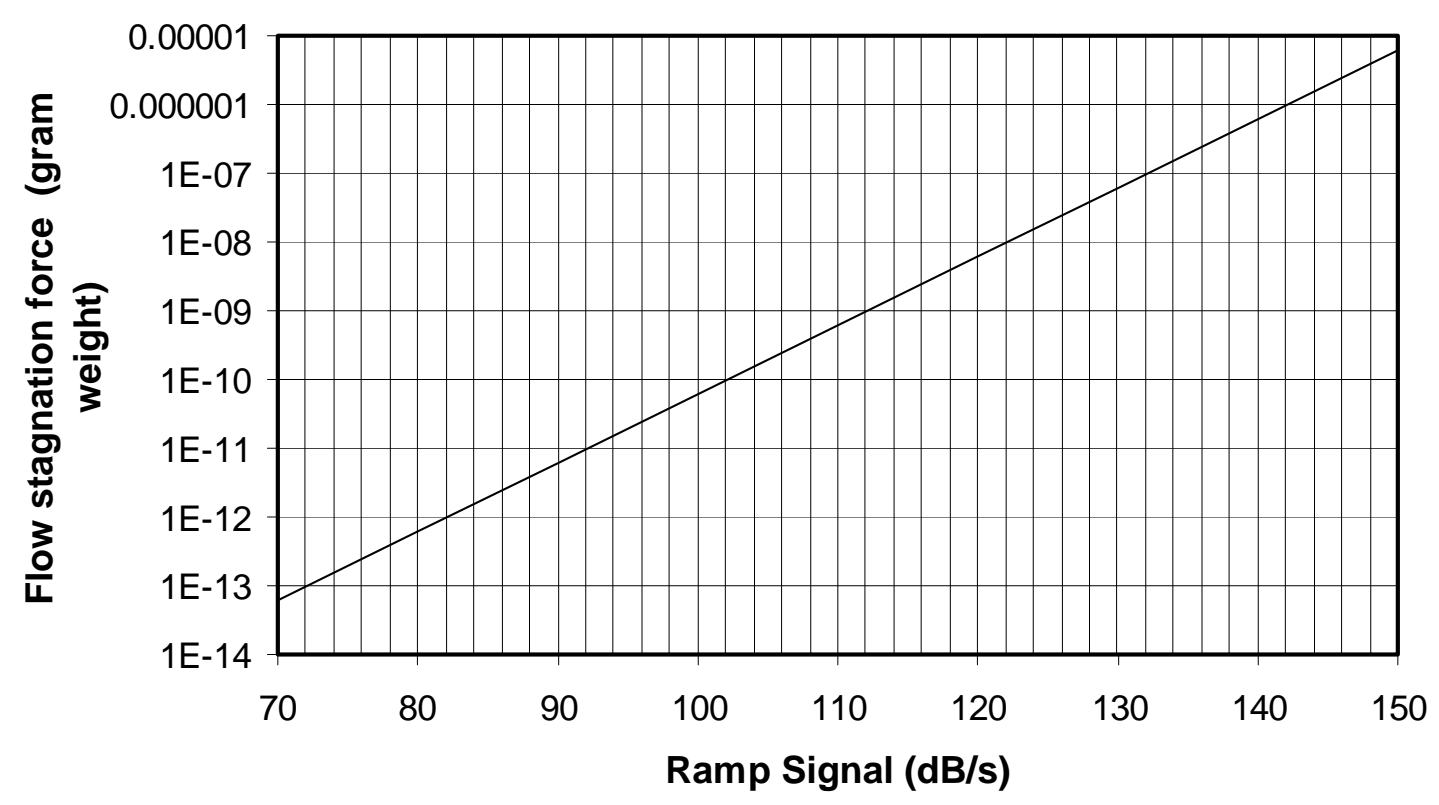

Fig 4.7: Flow Stagnation Force in $1 / 2$ inch Pipe as a Function of Stagnation Pressure in dB.

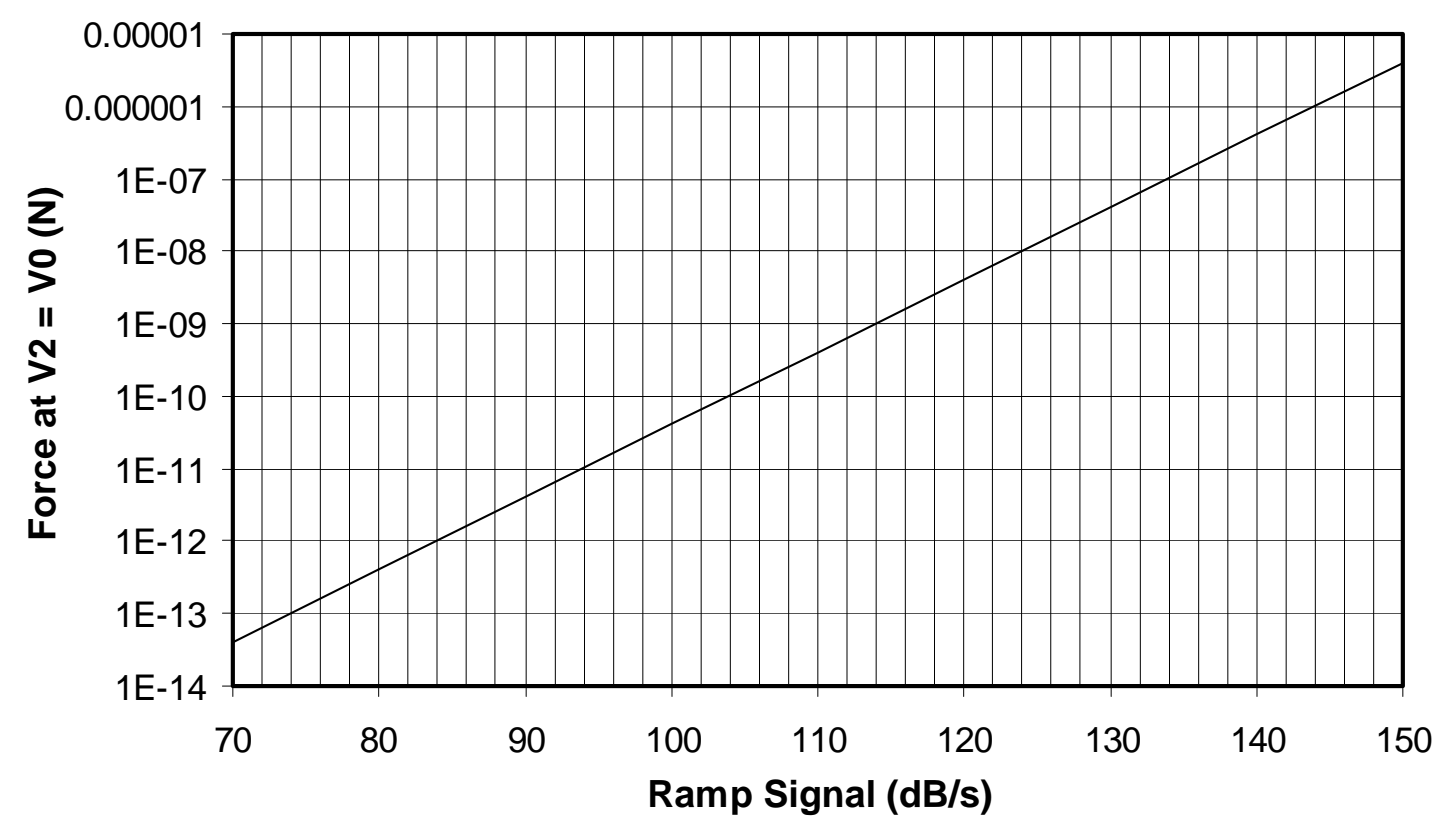

Fig 4.8: Force on the Diaphragm at V $2=\mathrm{Vo}$ as a Function of Stagnation Pressure in $\mathrm{dB}$ for an Air Filled Line. 


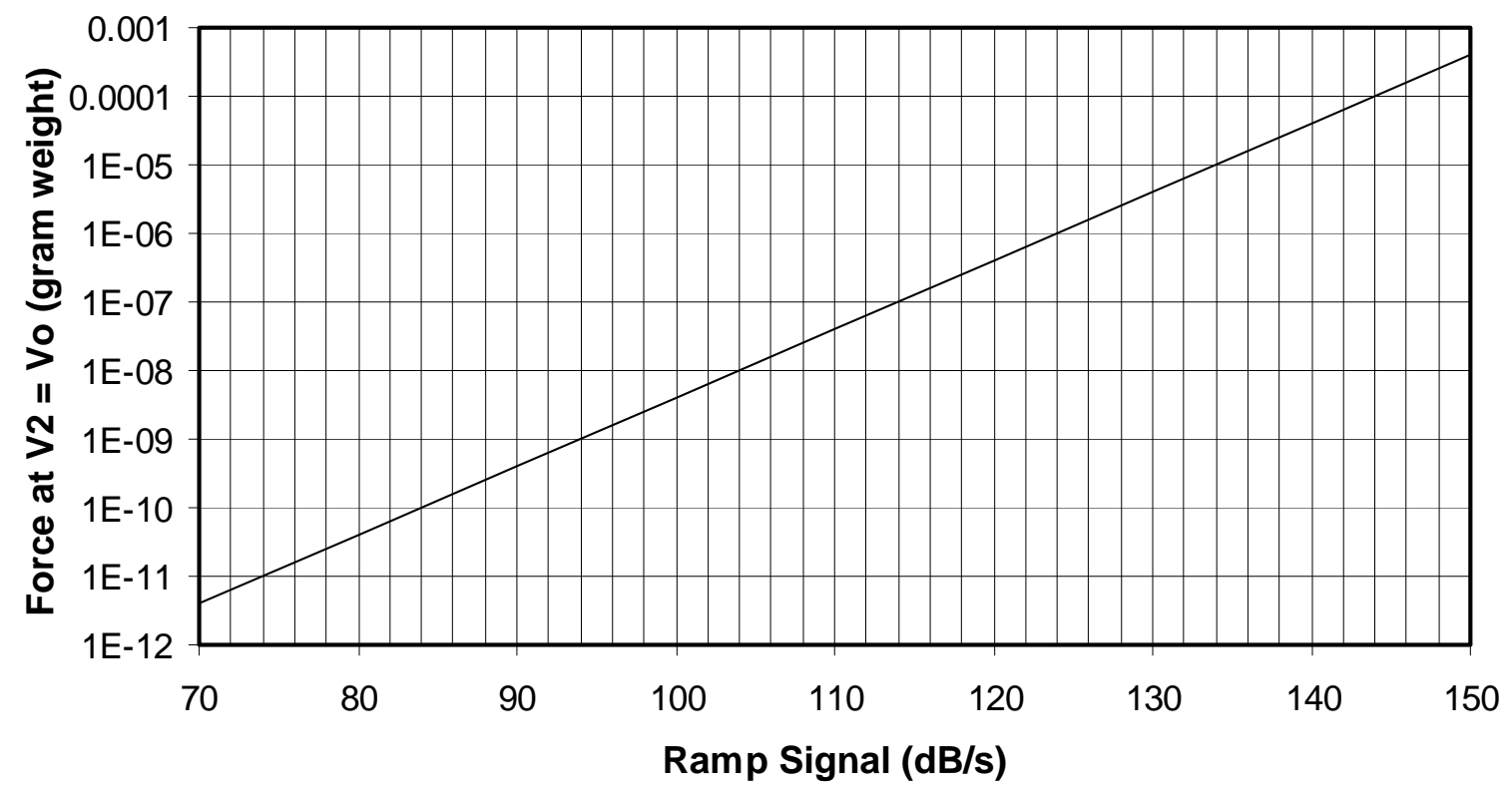

Fig 4.9: Force on Diaphragm as a Function of Stagnation Pressure in $\mathrm{dB}$ at V2 = Vo.

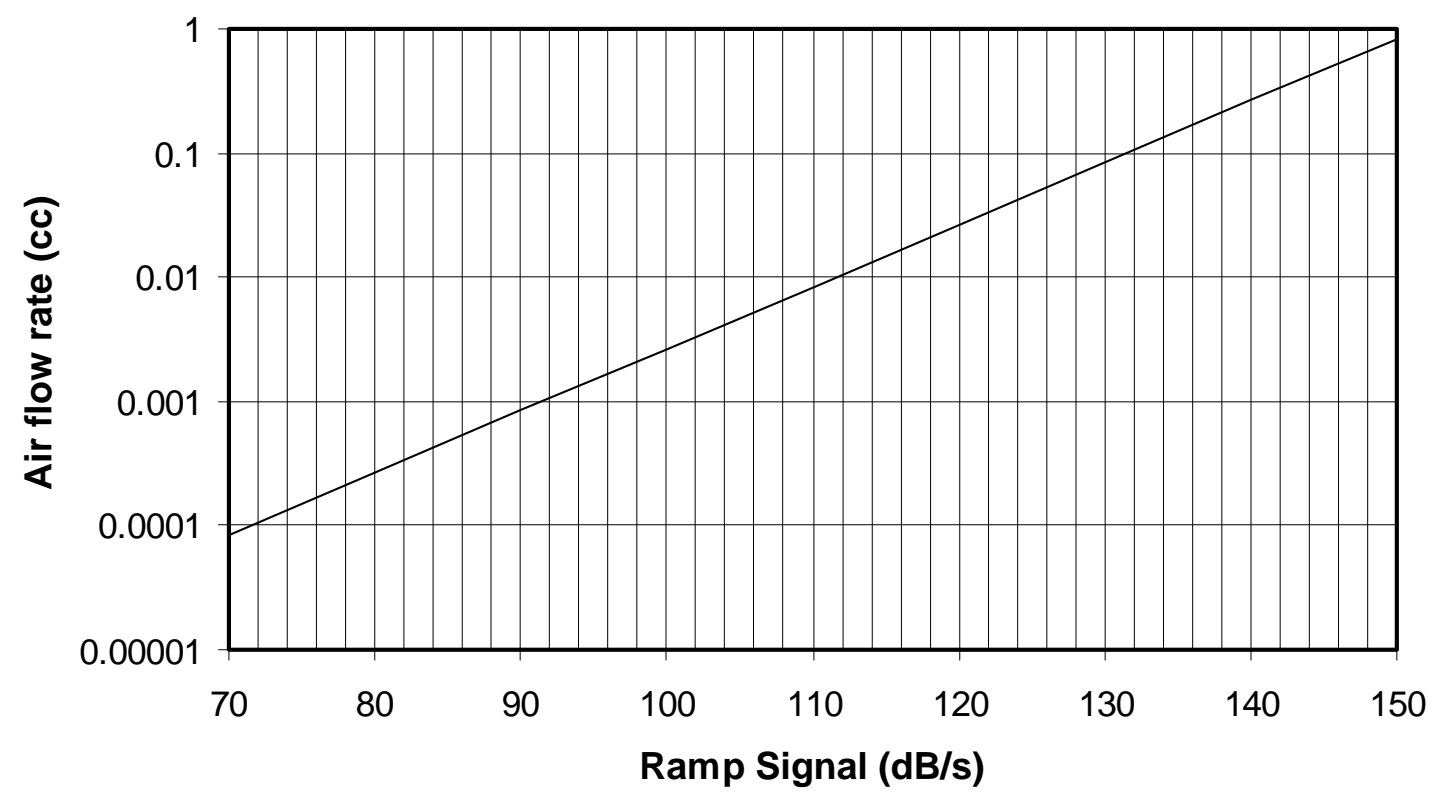

Fig 4.10: Air Flow Rate at 1 Atmosphere as a Function of Stagnation Pressure in $\mathrm{dB}$ for Gap = $0.542 \mathrm{~mm}$. 


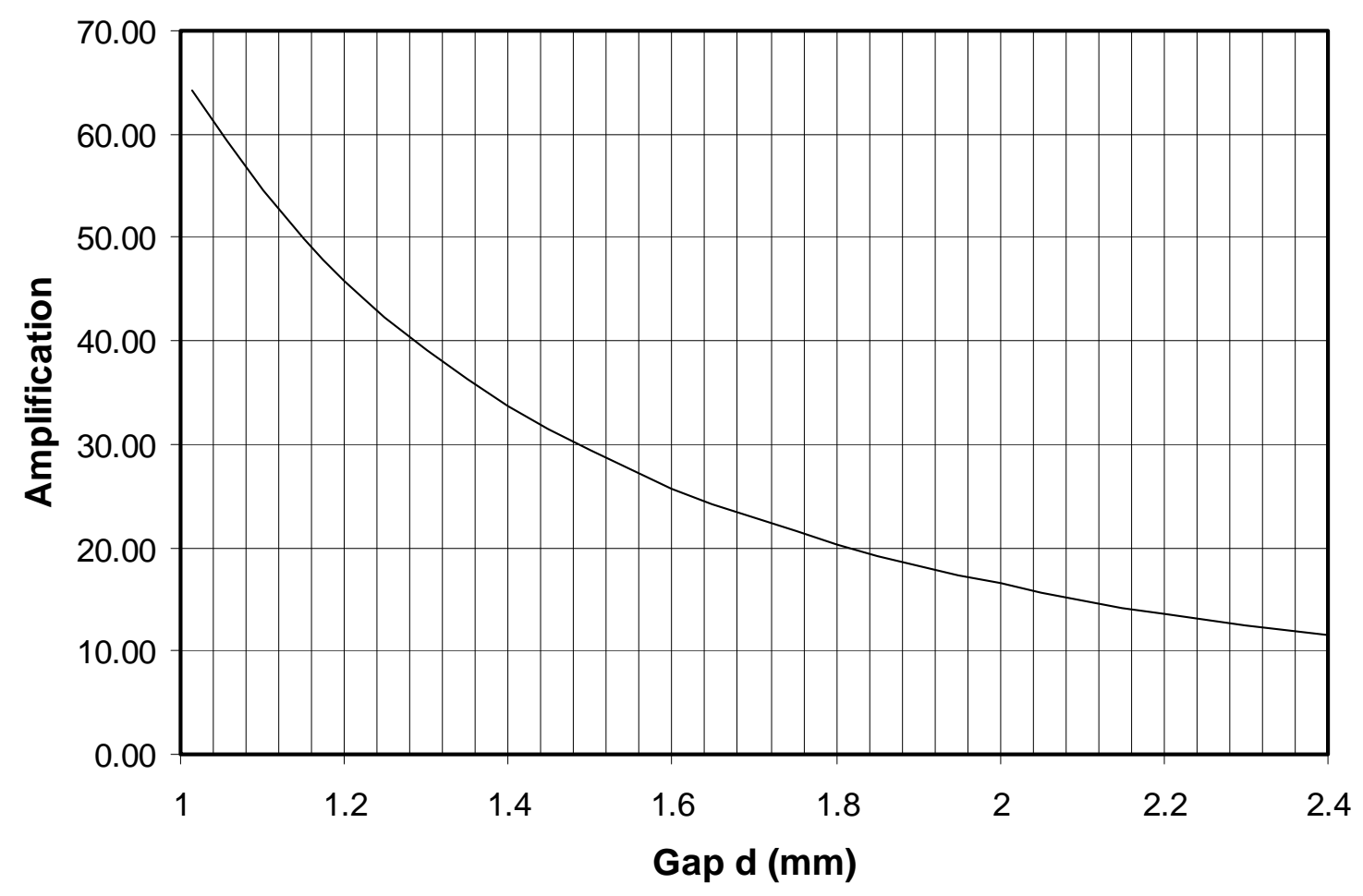

Fig 4.11: Diaphragm Force Amplification as a Function of Gap d (mm).

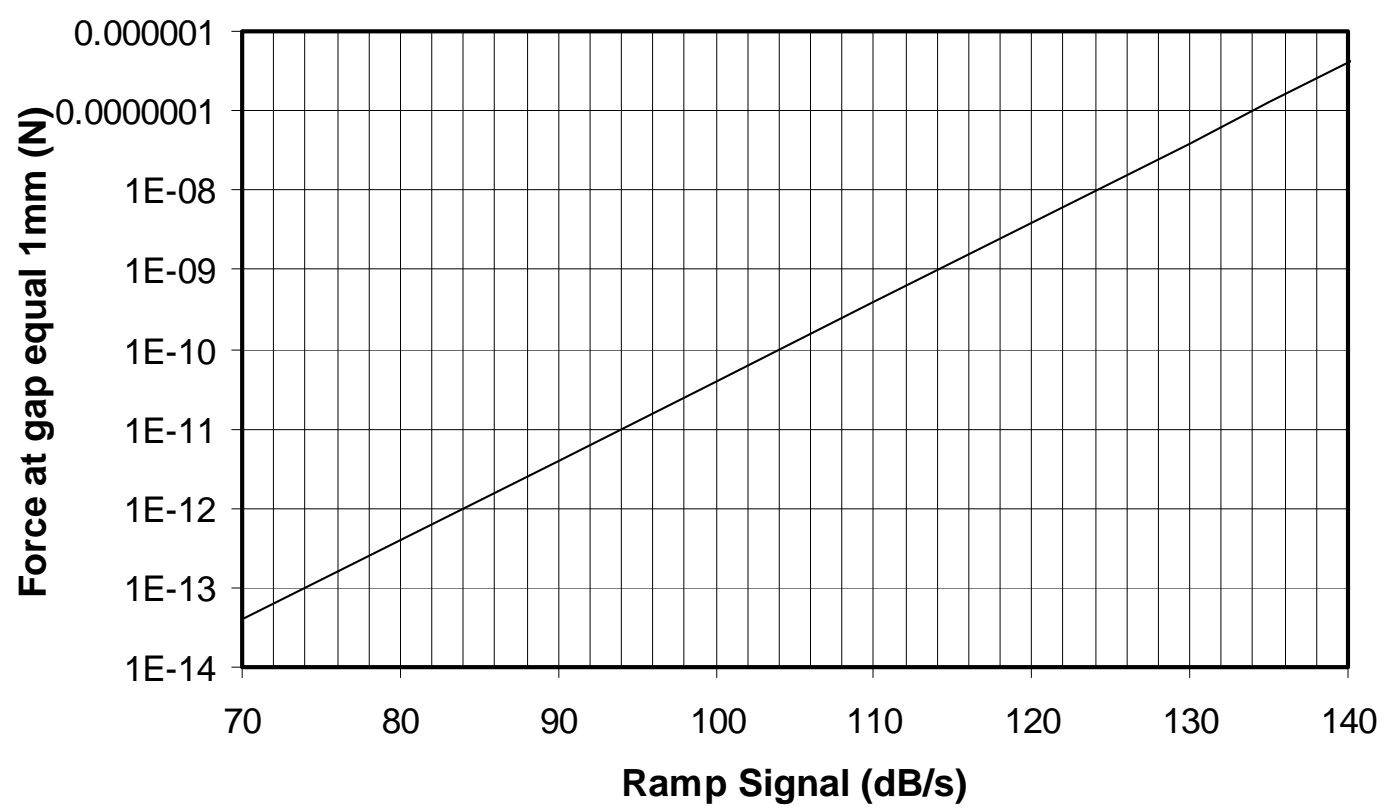

Figure 4.12: Force at Gap Equal 1mm as a Function of Stagnation Pressure in dB. 


\section{Diaphragm Deflection}

This section describes the diaphragm deflection and deflection angle calculations as a function of force Fs. The flow in the $1 / 2$ inch pipe causes the diaphragm to deflect by an angle $\theta$. The diaphragm deflects in a spherical shape with $\mathrm{R}$ being the radius of curvature (see fig). The geometry of the curvature gives

$\operatorname{Sin} \theta=\frac{r}{R}$

The strain in the diaphragm is given by the difference in outer and the inner arc length e.

Or e $=\frac{R-(R-0.5 * t)}{R}=\frac{0.5 * t}{R}$

Also $e=\frac{\sigma}{E}$, which gives $\sigma=\frac{0.5 * t^{*} E}{R}$

The vertical component of the tensile stress $\sigma$ times the area gives the net force $F_{s}$ on the diaphragm.

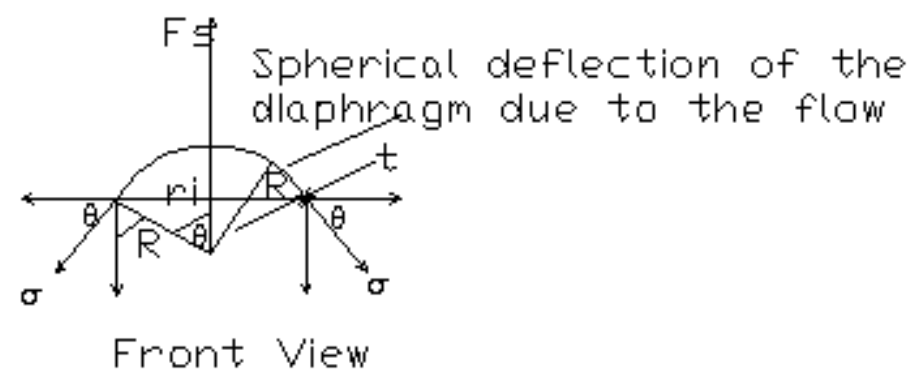

Fig 4.13: Spherically Deflected Diaphragm.

Thus $F_{s}=\sigma *\left(2 * \pi * r_{i}^{*} t * \sin \theta\right)$

Deflection at the center is given by putting the value of $\sigma$ in the force equation gives 
$F_{s}=\frac{0.5 * t * E}{R} *\left(2 * \pi * r_{i} * t * \sin \theta\right)=\frac{0.5 * t * E}{R} *\left(2 * \pi * r_{i} * t * \frac{r_{i}}{R}\right)$

or $F_{s}=\frac{0.5 * E * 2 * \pi * r_{i}^{2} * t^{2}}{R^{2}}$

This can be solved to obtain $\mathrm{R}$ or

$\mathrm{R}=t * r_{i} * \sqrt{\frac{E \pi}{F_{s}}}$

$\delta=\mathrm{R}-\mathrm{R} * \cos \theta=\mathrm{R}(1-\cos \theta)=\mathrm{R}\left(1-\left(\sqrt{1-\sin ^{2} \theta}\right)\right)$

Or $\delta=\operatorname{R}\left(1-\left(\sqrt{1-\frac{r_{i}^{2}}{R^{2}}}\right)\right)$

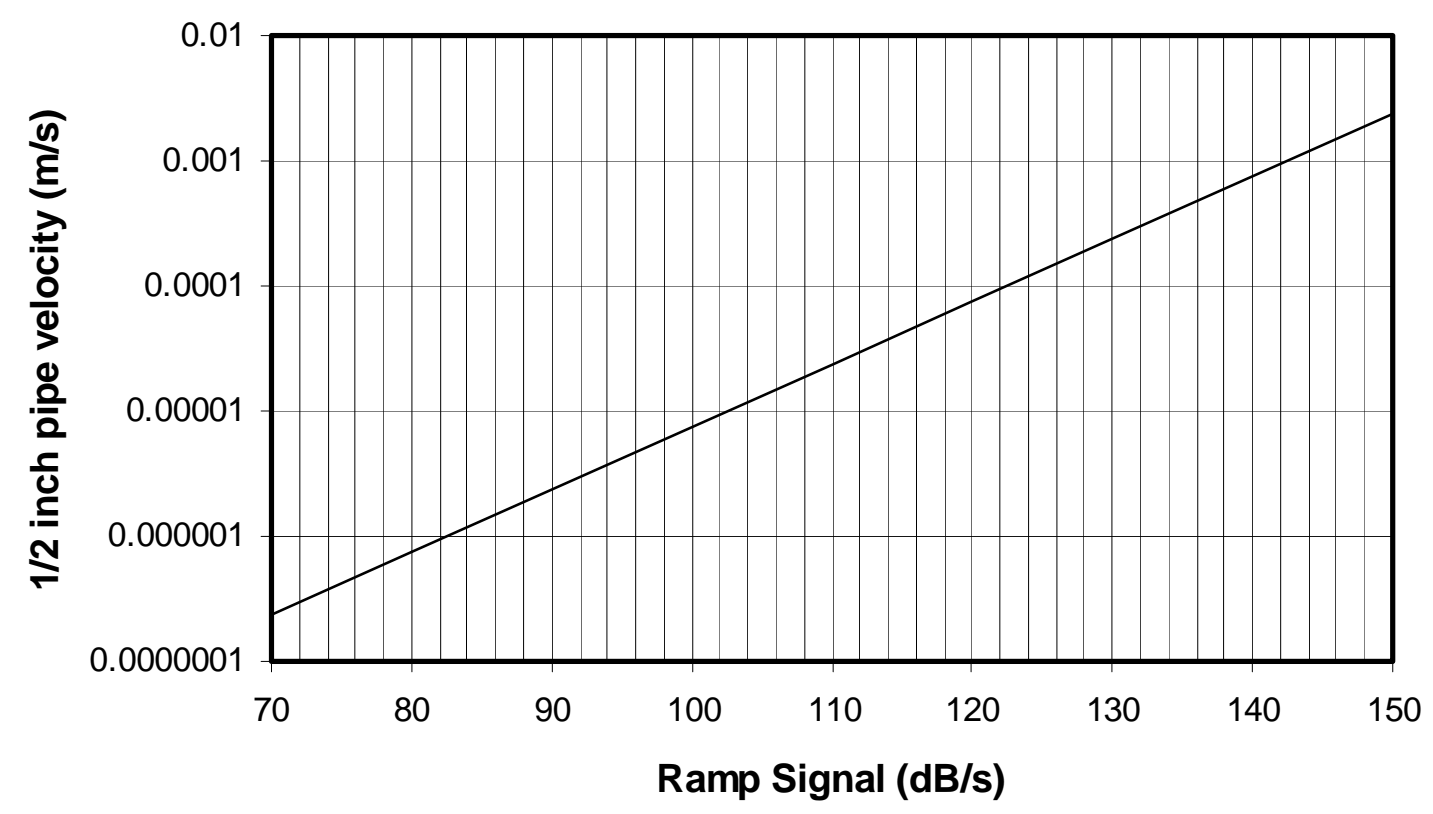

Fig 4.14: $1 / 2$ inch Pipe Velocity Vo as a Function of Stagnation Pressure in dB at $1 \mathrm{~atm}$. 


\begin{tabular}{|c|c|c|c|c|c|c|}
\hline $\begin{array}{c}\text { Ramp } \\
\text { signal (-- } \\
\text { Db/s) }\end{array}$ & Force Fs (N) & $R(m)$ & Deflection (m) & Deflection $(\mathrm{mm})$ & Theta (radians) & Stress $\left(N / m^{\wedge} 2\right)$ \\
\hline 10 & 1.08184E-20 & $2.6684 \mathrm{E}+10$ & 0 & 0 & 1.46155E-09 & 0.00047594 \\
\hline 20 & $1.08184 \mathrm{E}-19$ & 8438226261 & 0 & 0 & 4.62182E-09 & 0.001505056 \\
\hline 30 & $1.08184 \mathrm{E}-18$ & 2668401440 & 0 & 0 & 1.46155E-08 & 0.004759404 \\
\hline 40 & $1.08184 \mathrm{E}-17$ & 843822626 & 0 & 0 & 4.62182E-08 & 0.015050556 \\
\hline 50 & $1.08184 \mathrm{E}-16$ & 266840144 & 0 & 0 & $1.46155 \mathrm{E}-07$ & 0.047594038 \\
\hline 60 & $1.08184 \mathrm{E}-15$ & 84382262.6 & 0 & 0 & 4.62182E-07 & 0.150505564 \\
\hline 70 & $1.08184 \mathrm{E}-14$ & 26684014.4 & 0 & 0 & 1.46155E-06 & 0.475940382 \\
\hline 80 & $1.08184 \mathrm{E}-13$ & 8438226.26 & 0 & 0 & 4.62182E-06 & 1.505055637 \\
\hline 90 & $1.08184 \mathrm{E}-12$ & 2668401.44 & 2.96252E-10 & 2.96252E-07 & $1.46155 \mathrm{E}-05$ & 4.759403818 \\
\hline 100 & $1.08184 \mathrm{E}-11$ & 843822.626 & $9.36831 \mathrm{E}-10$ & 9.36831E-07 & 4.62182E-05 & 15.05055637 \\
\hline 110 & $1.08184 \mathrm{E}-10$ & 266840.144 & 2.84402E-09 & 2.84402E-06 & 0.000146155 & 47.59403818 \\
\hline 120 & 1.08184E-09 & 84382.2626 & 9.01232E-09 & 9.01232E-06 & 0.000462182 & 150.5055637 \\
\hline 130 & $1.08184 \mathrm{E}-08$ & 26684.0144 & 2.84994E-08 & 2.84994E-05 & 0.001461549 & 475.9403818 \\
\hline 140 & 1.08184E-07 & 8438.22626 & $9.0125 \mathrm{E}-08$ & $9.0125 \mathrm{E}-05$ & 0.004621824 & 1505.055637 \\
\hline 150 & $1.08184 \mathrm{E}-06$ & 2668.40144 & 2.85002E-07 & 0.000285002 & 0.014615492 & 4759.403818 \\
\hline
\end{tabular}

Table 4.6: Table Showing Variation of Deflection Angle, Force and Stress with Stagnation Pressure. 


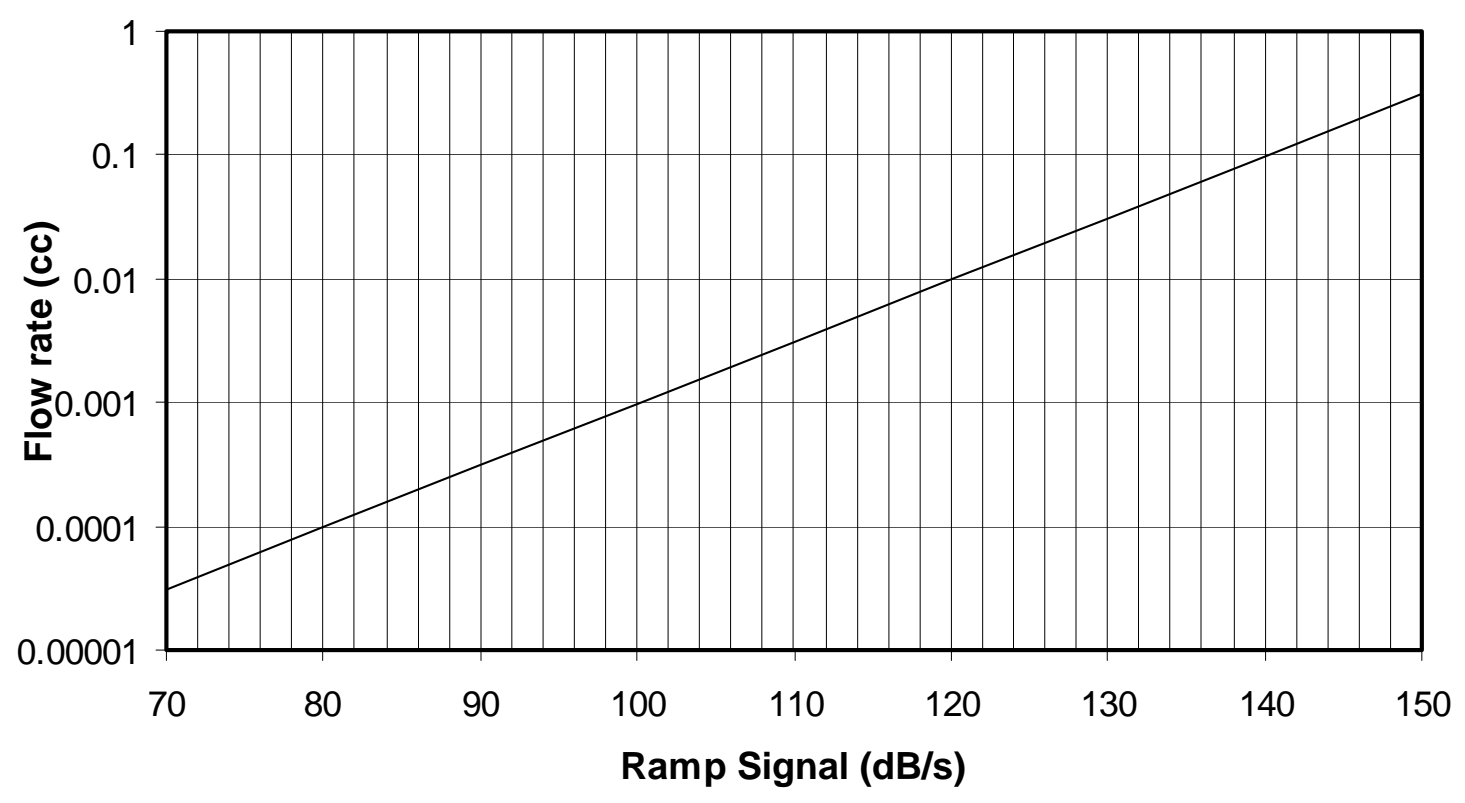

Fig 4.15: Methane Flow Rate at 10 Atmosphere as a Function of Stagnation Pressure in dB.

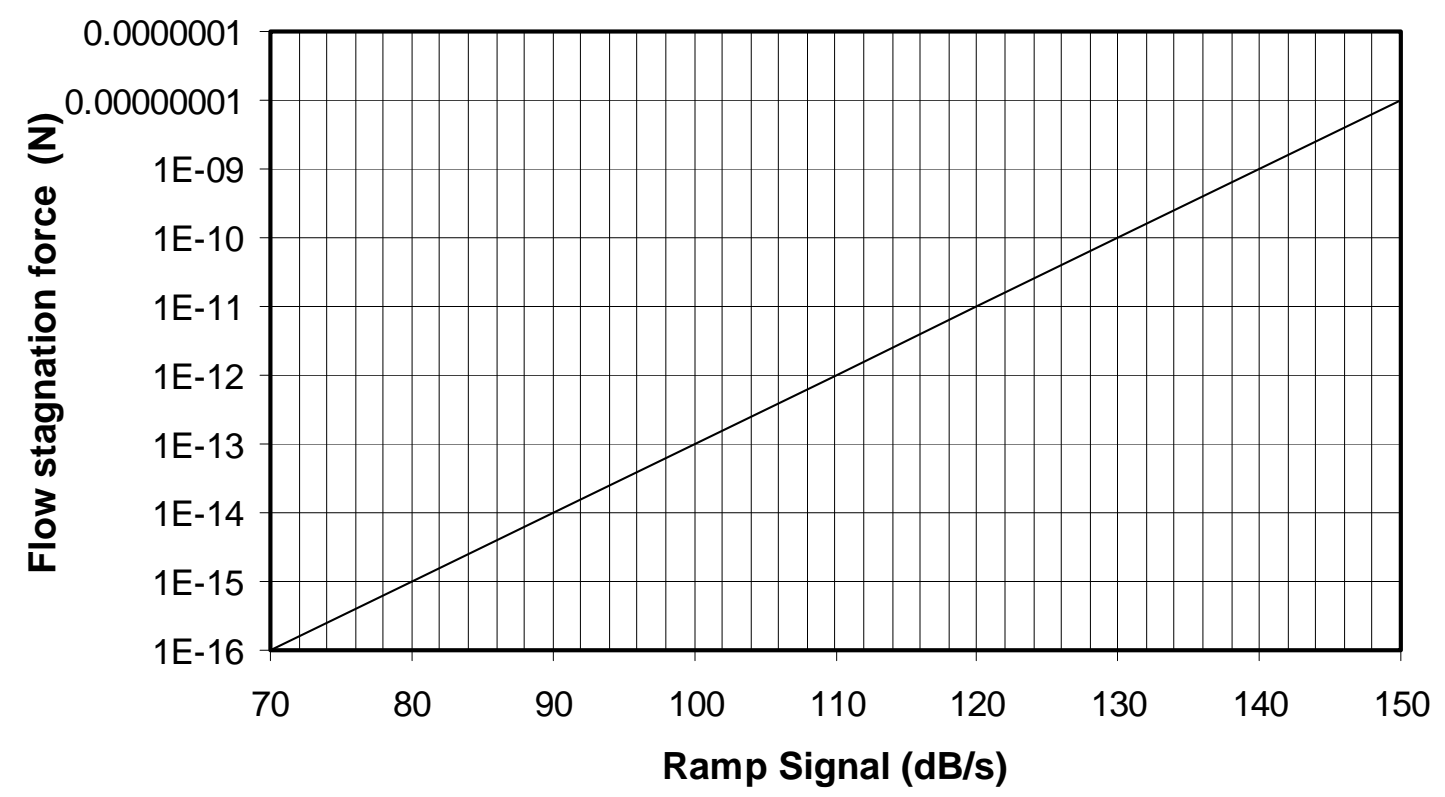

Fig 4.16: Flow Stagnation Force in $1 / 2$ Inch Pipe as a Function of Stagnation Pressure in $\mathrm{dB}$ for Methane Filled line at $1 \mathrm{~atm}$. 


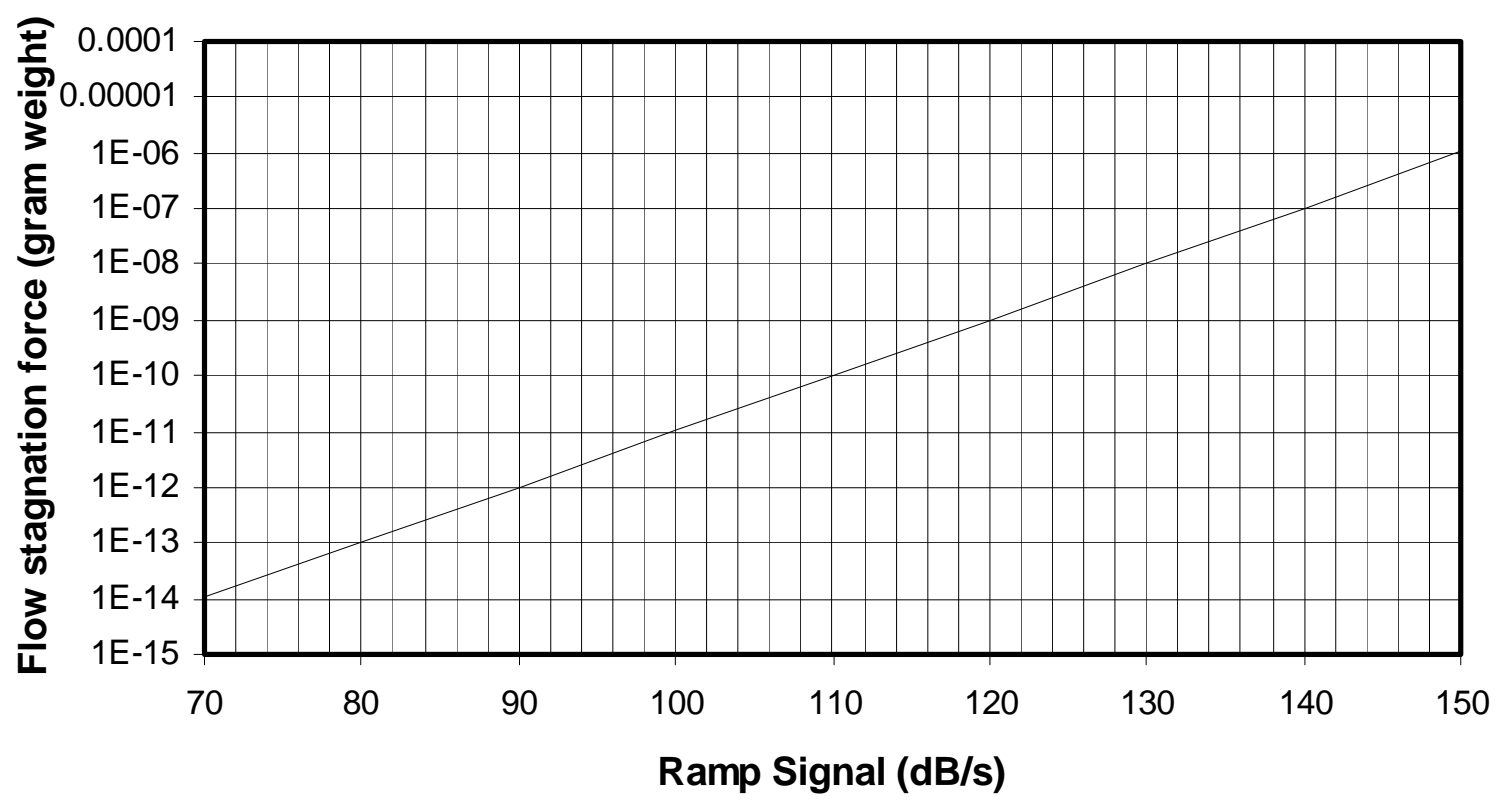

Fig 4.17: Flow Stagnation Force in $1 / 2$ Inch Pipe as a Function of Stagnation Pressure in $\mathrm{dB}$ for Methane Filled line.

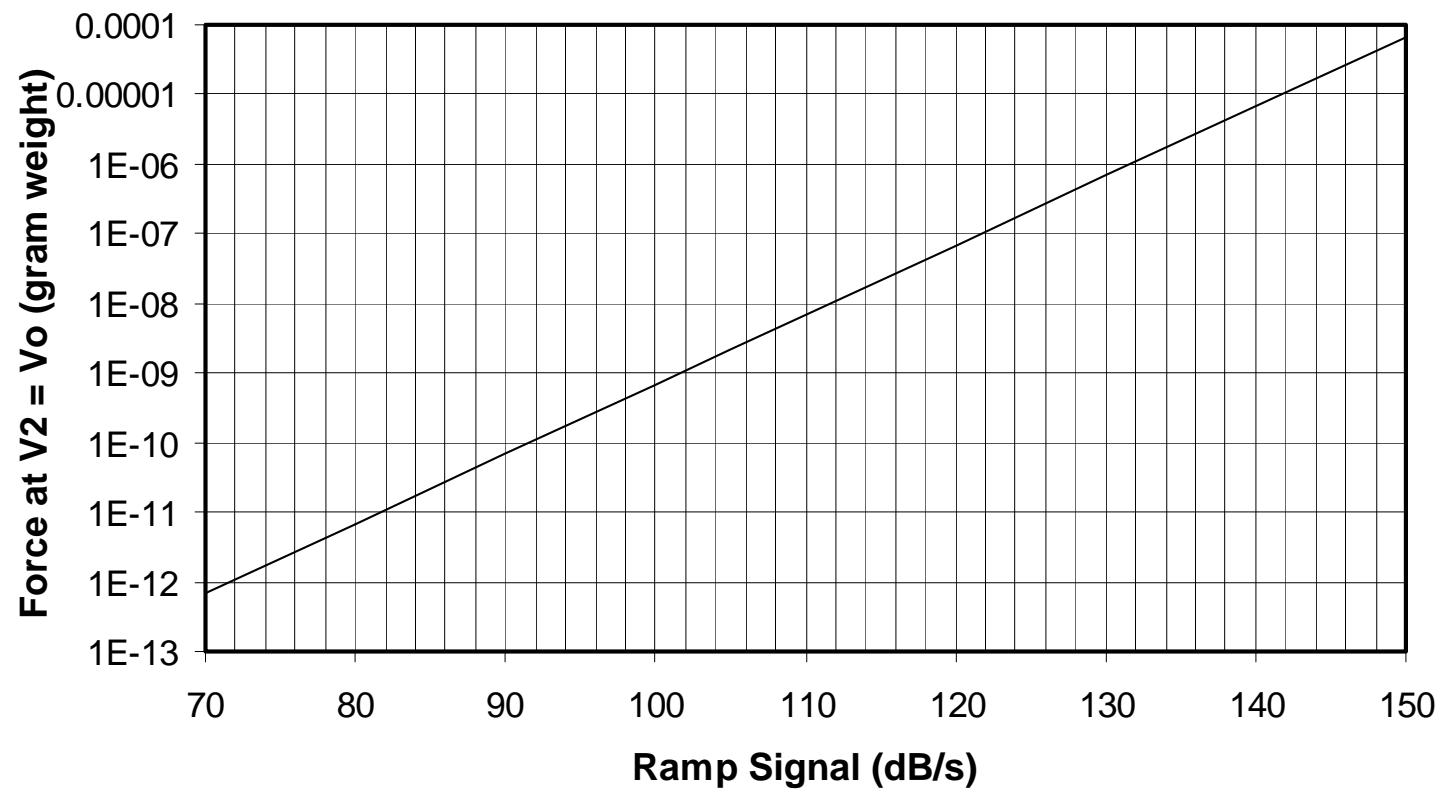

Fig 4.18: Force on the Diaphragm as a Function of Stagnation Pressure in $\mathrm{dB}$ for Methane Filled Line. 


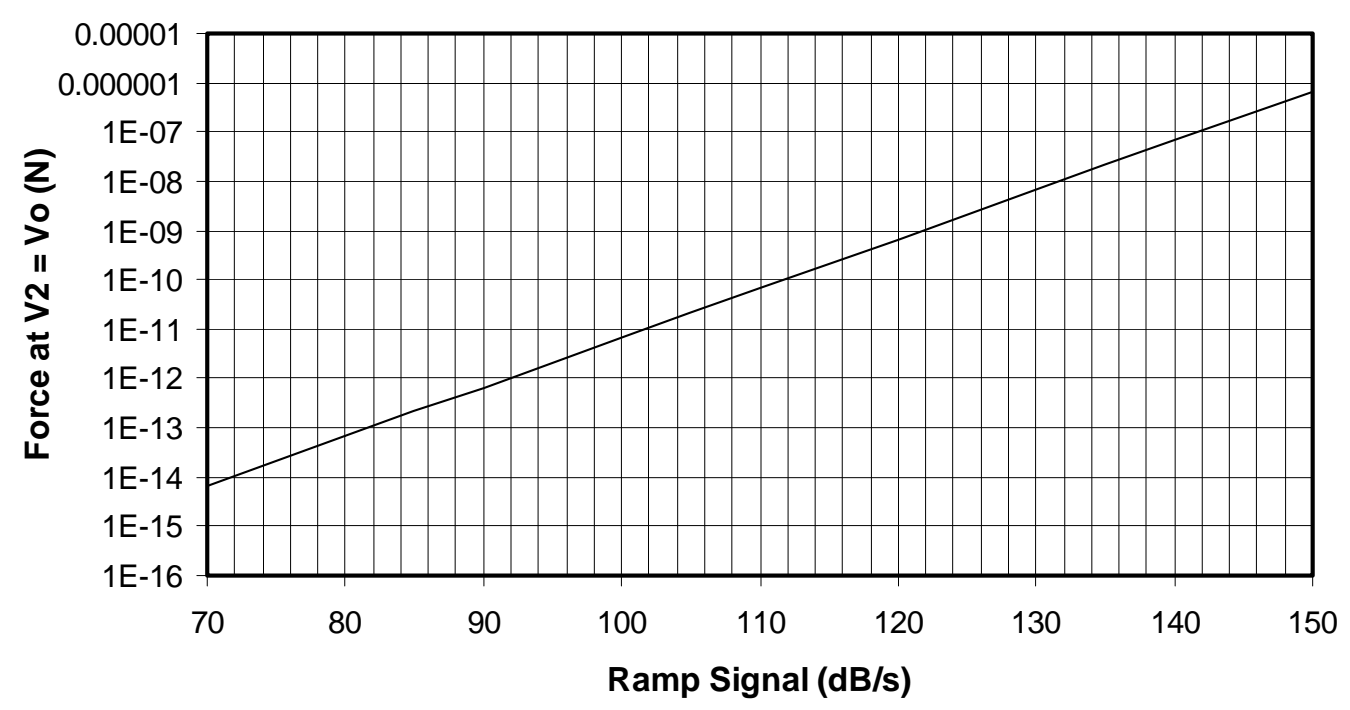

Fig 4.19: Force on the Diaphragm as a Function of Stagnation Pressure in dB for Methane Filled

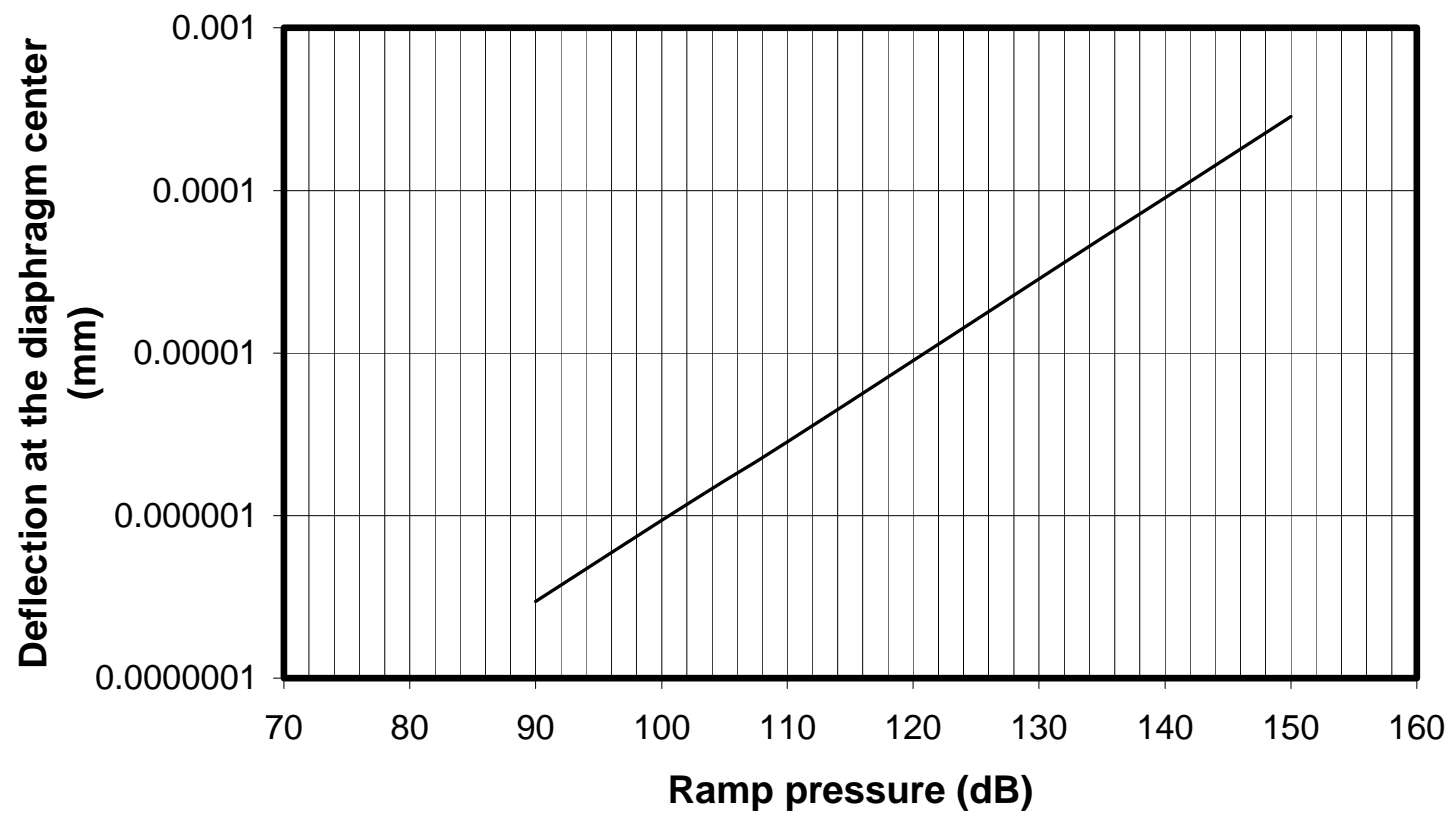

Fig 4.20: Center Deflection of Diaphragm as a Function of Acoustic Pressure. 


\section{Diaphragm Deflection Measuring Beam}

A cantilever beam was designed to measure diaphragm deflection, which was the same material as the diaphragm. One end of the beam was soldered to a rigid support while the other end was hanging freely. A screw soldered to the center of the diaphragm was positioned in such a manner that the motion of the screw due to the diaphragm deflection would deflect the free end of the cantilever. This deflection could be given by the Castigliano's theorem (Timoshenko)

$$
\text { Deflection } \delta=\frac{P^{*} L^{3}}{3^{*} E^{*} I}
$$

where $\mathrm{P}$ is the force at the loaded end, $\mathrm{L}$ is the length of the beam

Moment $\mathrm{M}=\mathrm{P}^{*} \mathrm{~L}$, is the maximum bending moment when $\mathrm{P}$ is the critical load

Stress $\sigma=\frac{P^{*} L^{*} t}{2 * I}=\frac{M * t}{2 * I}$

is the critical stress, $\mathrm{t}$ is the height of the beam.

$\mathrm{I}=\frac{b^{*} t^{3}}{12}=1.083 \mathrm{e}-15$, is the moment of inertia for a rectangular beam where $\mathrm{b}$ is the width of the beam and is equal to $1 / 4$ inch $=.00635 \mathrm{~m}$

$$
\begin{aligned}
& \text { Also } \delta=\frac{2 * L^{2} * \sigma}{3 * E * t} \\
& \text { or } \mathrm{L}=\sqrt{\frac{3 * E * t * \delta}{2 * \sigma}}=\sqrt{\frac{3 * 1 * 10^{11} \cdot .000127 * .001}{2 * 2.5 * 10^{7}}}=0.028 \mathrm{~m}
\end{aligned}
$$

Moment $\mathrm{M}=\frac{2 * I * \sigma}{t}=\frac{2 * 1.083 * 10^{-15} * 2.5 * 10^{7}}{.000127}=4.27 \mathrm{e}-4 \mathrm{Nm}$

Thus maximum force $\mathrm{P}=\frac{M}{L}=\frac{4.27 * 10^{-4}}{.028}=.01525 \mathrm{~N}$ 
Thus Strain ,e $=\frac{\sigma}{E}=4.27 \mathrm{e}-15$ 


\section{Chapter 5}

\section{Experimental Procedure}

\section{Source Flow Acoustic Signal Amplifier}

The inviscid theory in chapter four gives the suction force Fs.

Suction Force, $F_{s}=\frac{1}{2} \pi \rho r_{o}^{2} V_{2}^{2}\left(2 \ln \left(\frac{r_{2}}{r_{1}}\right)-1+\frac{r_{1}^{2}}{r_{2}^{2}}\right) r_{d}$

Since the gap acts as a venturi the pressure increases from the inlet to the outlet. Due to friction all

the kinetic energy does not get converted into pressure and the recovered pressure is less than the inlet pressure. Thus the total recovery factor rd is the ratio of outlet dynamic pressure to the total inlet dynamic pressure. The outlet dynamic pressure can be calculated from the calculated suction force. The inlet total pressure was given by the manometer.

Continuity gives mdot $=A_{2} \rho V_{2}=2 \pi r_{2} d \rho V_{2}$

also mdot $=A_{o} \rho V_{o}=\pi r^{2}{ }_{o} \rho V_{o}$

$V_{o}=\frac{m d o t}{\pi r^{2}{ }_{0} \rho}=\frac{2 \pi r_{2} d \rho V_{2}}{\pi r^{2}{ }_{o} \rho}=\frac{2 r_{2} d V_{2}}{r^{2}{ }_{o}}=\frac{d V_{2}}{1.1013}$ where d is in $\mathrm{mm}$.

or $\frac{V_{2}}{V_{o}}=\frac{1.013}{d}$, also $\mathrm{r}_{\mathrm{d}}=\frac{\left(\frac{1}{2} \rho V_{2}^{2}\right)_{\text {outlet }}}{(\Delta P)_{\text {manometer }}}$

Using the same method as used in chapter four to calculate force amplification we get

For $r_{1}=.011 \mathrm{~m}, r_{2}=.039 \mathrm{~m}, r_{0}=.00889 \mathrm{~m} A_{\text {amp }}=\frac{15}{d^{2}}$

and $\left(\frac{1}{2} \rho V_{2}^{2}\right)_{\text {outlet }}=\frac{F_{s}}{.0076}, F_{s}=F_{o}+\mathrm{W}$ and $\mathrm{W}=$ weight carried by the diaphragm 
Also $\mathrm{T}=288 \mathrm{k}, \mathrm{P}=101325 \mathrm{~Pa}, \rho=1.225 \mathrm{~kg} / \mathrm{m}^{\wedge} 3$

Table 5.1 below shows flow rate (cfm), weight (grams), inlet total pressure (inches H20) obtained from the experiments. In table 5.2 these values have been converted into metric units. Fig $5.1 \& 5.2$ shows the graphs of flow rate and $\Delta$ Pmanometer as a function of weight. Table 5.3 shows the values calculated values of gap d, velocity in the 0.7 inch diameter pipe Vo, outlet velocity $\mathrm{V} 2$, outlet pressure $\Delta \mathrm{P}$ and the pressure recovery factor rd.

Fig 5.3 shows the graph of amplification as a function of weight both theoretical and with friction losses obtained experimentally. Fig 5.4 shows the graph of calculated gap as a function of gap.

\begin{tabular}{|c|c|c|}
\hline $\begin{array}{l}\text { Flow Rate } \\
(\mathrm{cfm})\end{array}$ & $\begin{array}{l}\text { Weight } \\
\text { (grams) }\end{array}$ & $\begin{array}{c}\text { Pmanometer } \\
\text { (inches H20) }\end{array}$ \\
\hline 4 & 7 & 1.25 \\
\hline 5.7 & 21 & 2.7 \\
\hline 6.2 & 27.5 & 4.3 \\
\hline 6.6 & 36 & 5 \\
\hline 7 & 43.5 & 5.5 \\
\hline
\end{tabular}

Table 5.1: Table Showing Values Obtained from the Experiment. 


\begin{tabular}{|c|c|c|}
\hline $\begin{array}{c}\text { Force } \\
(\mathrm{N})\end{array}$ & $\begin{array}{c}\text { Pressure } \\
\left(\mathrm{N} / \mathrm{m}^{\wedge} 2\right)\end{array}$ & $\begin{array}{c}\text { Flow Rate } \\
\left(\mathrm{m}^{\wedge} 3 / \mathrm{s}\right)\end{array}$ \\
\hline 0.1 & 421.66 & 0.0021 \\
\hline 0.15 & 577.32 & 0.0023 \\
\hline 0.2 & 732.98 & 0.0025 \\
\hline 0.25 & 888.64 & 0.0027 \\
\hline 0.3 & 1044.3 & 0.0029 \\
\hline 0.35 & 1197 & 0.0031 \\
\hline 0.4 & 1355 & 0.0033 \\
\hline 0.45 & 1511 & 0.0035 \\
\hline
\end{tabular}

Table 5.2: Experimental Values Converted to Metric Units.

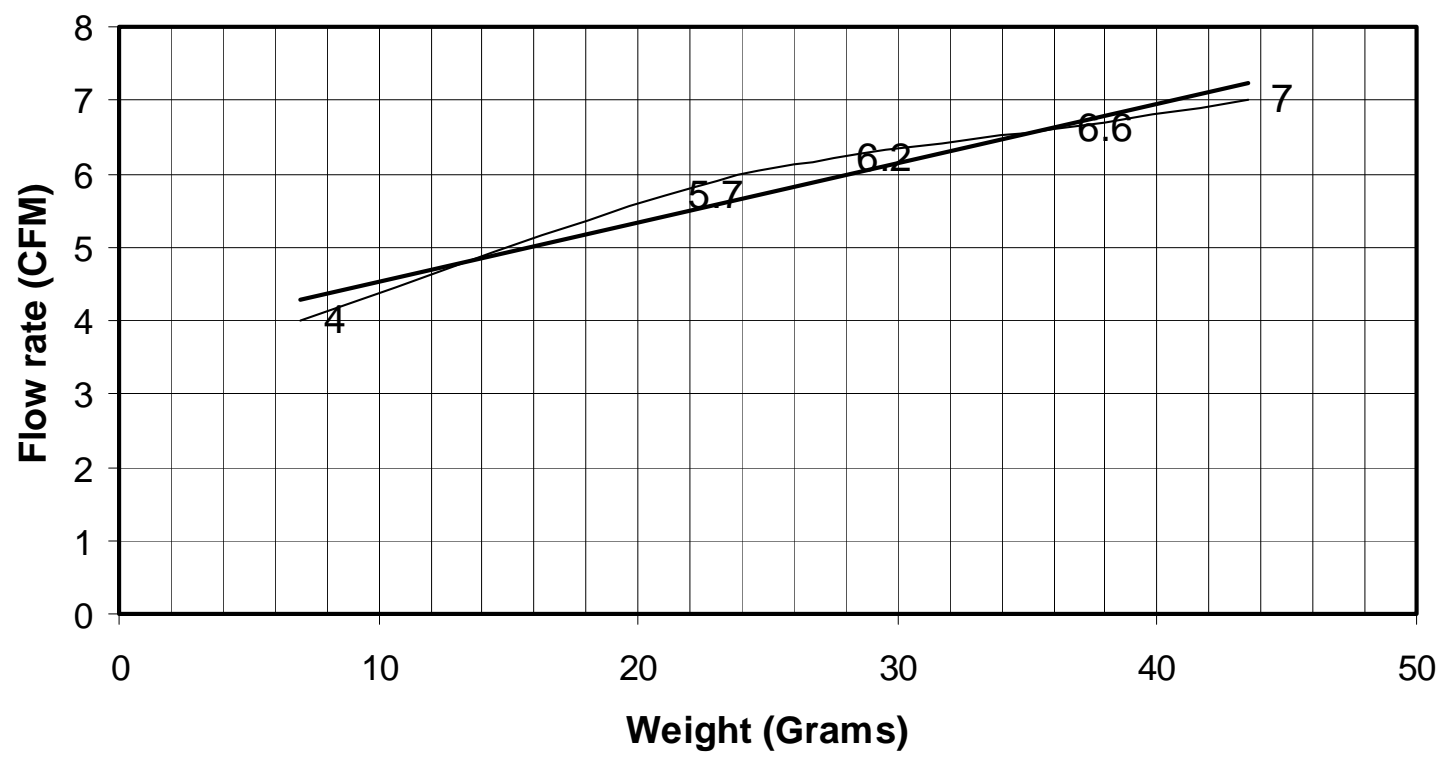

Fig 5.1: Linearized Experimental Data Points. 


\begin{tabular}{|c|c|c|c|c|}
\hline Gap & Vo & V2 & Poutlet & rd \\
\hline$(\mathrm{mm})$ & $(\mathrm{m} / \mathrm{s})$ & $(\mathrm{m} / \mathrm{s})$ & $\left(\mathrm{N} / \mathrm{m}^{\wedge} 2\right)$ & \\
\hline 1.144 & 8.041 & 7.118 & 31.033 & 0.034 \\
\hline 0.9977 & 8.826 & 8.961 & 49.19 & 0.038 \\
\hline 0.9286 & 9.612 & 10.48 & 67.35 & 0.04 \\
\hline 0.8915 & 10.39 & 11.81 & 85.51 & 0.041 \\
\hline 0.8708 & 11.18 & 13.01 & 103.67 & 0.042 \\
\hline 0.8598 & 11.97 & 14.1 & 121.83 & 0.0427 \\
\hline 0.8547 & 12.75 & 15.11 & 139.99 & 0.0432 \\
\hline 0.8537 & 13.54 & 16.06 & 158.15 & 0.0436 \\
\hline
\end{tabular}

Table 5.3: Calculated Values in Metric Units

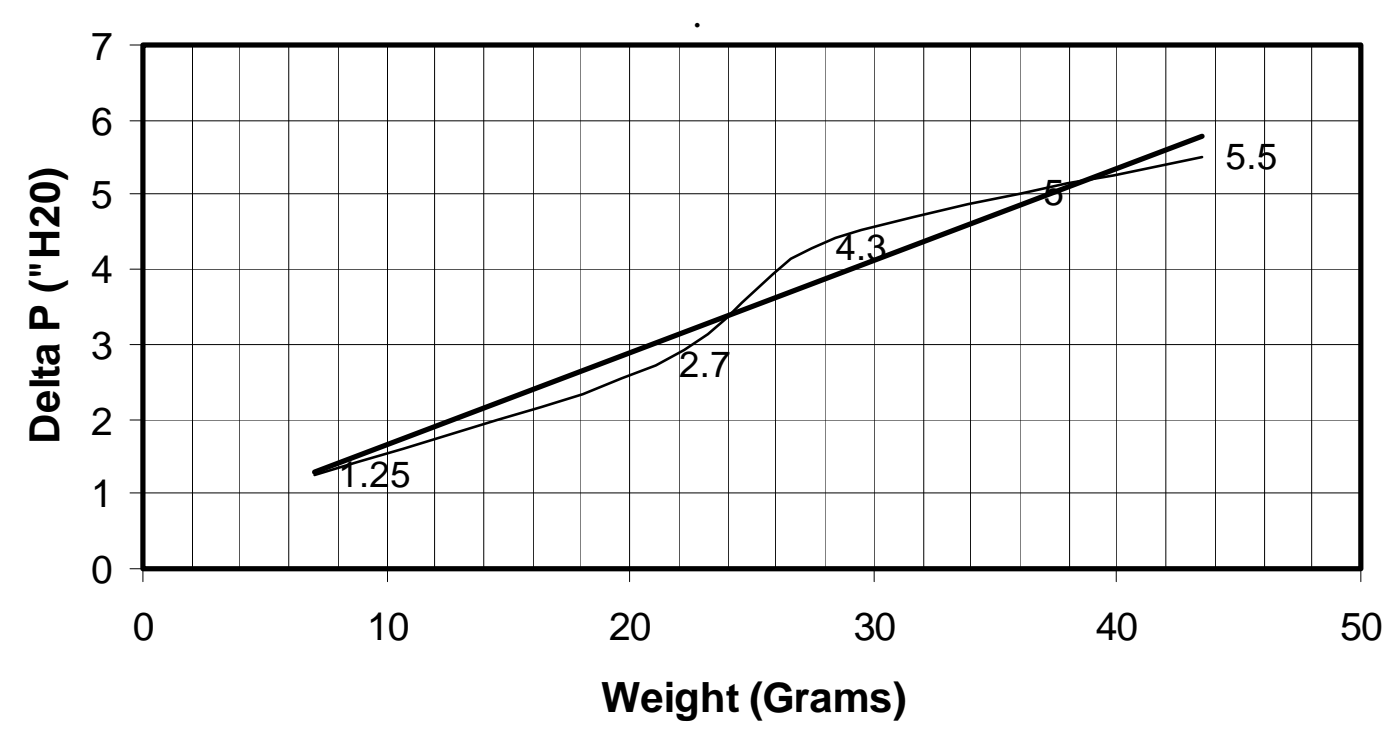

Fig 5.2: $\Delta P$ Inlet (inches $H 20$ ) Linearized Data Points. 


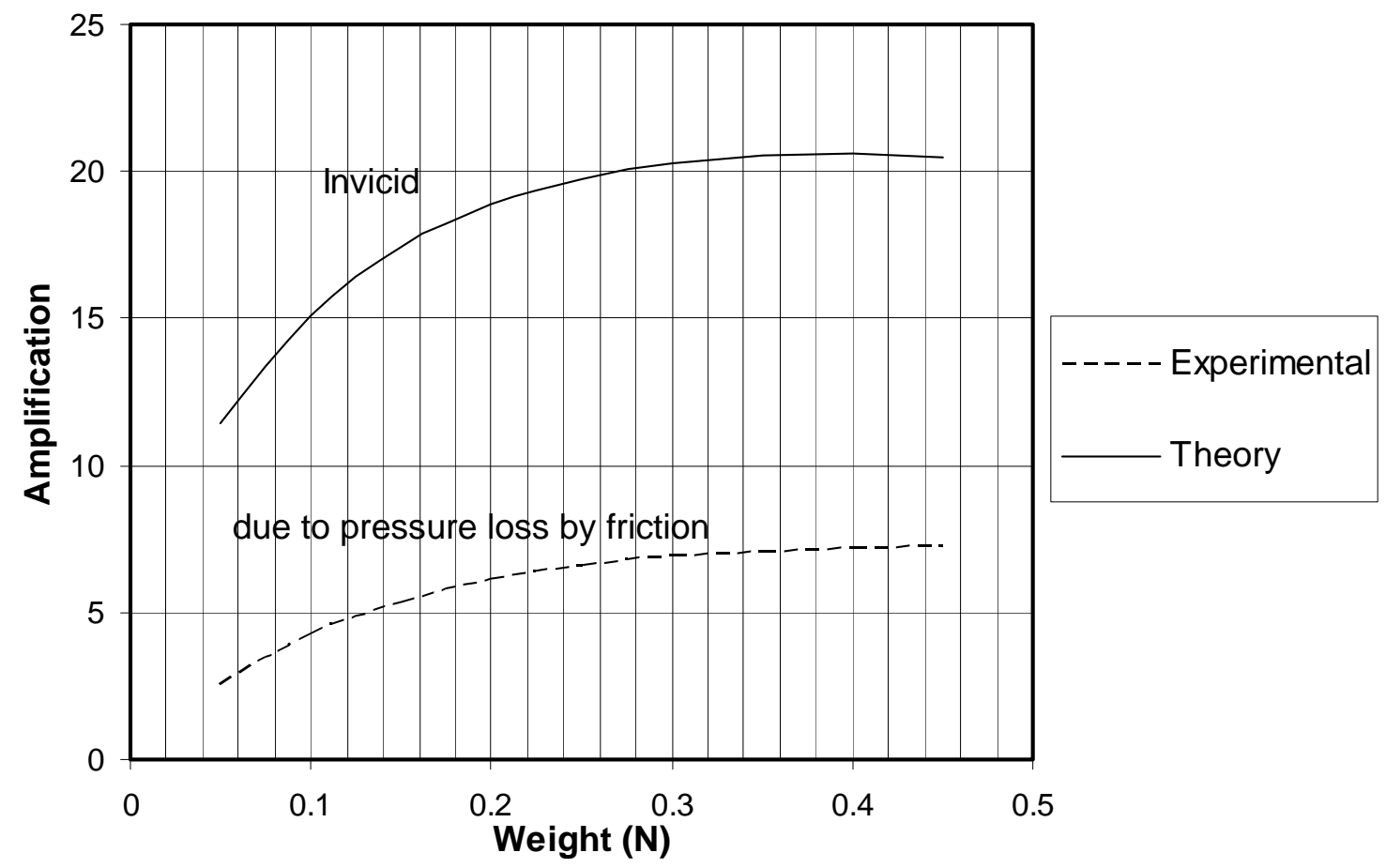

Fig 5.3: Amplification as a Function of Weight.

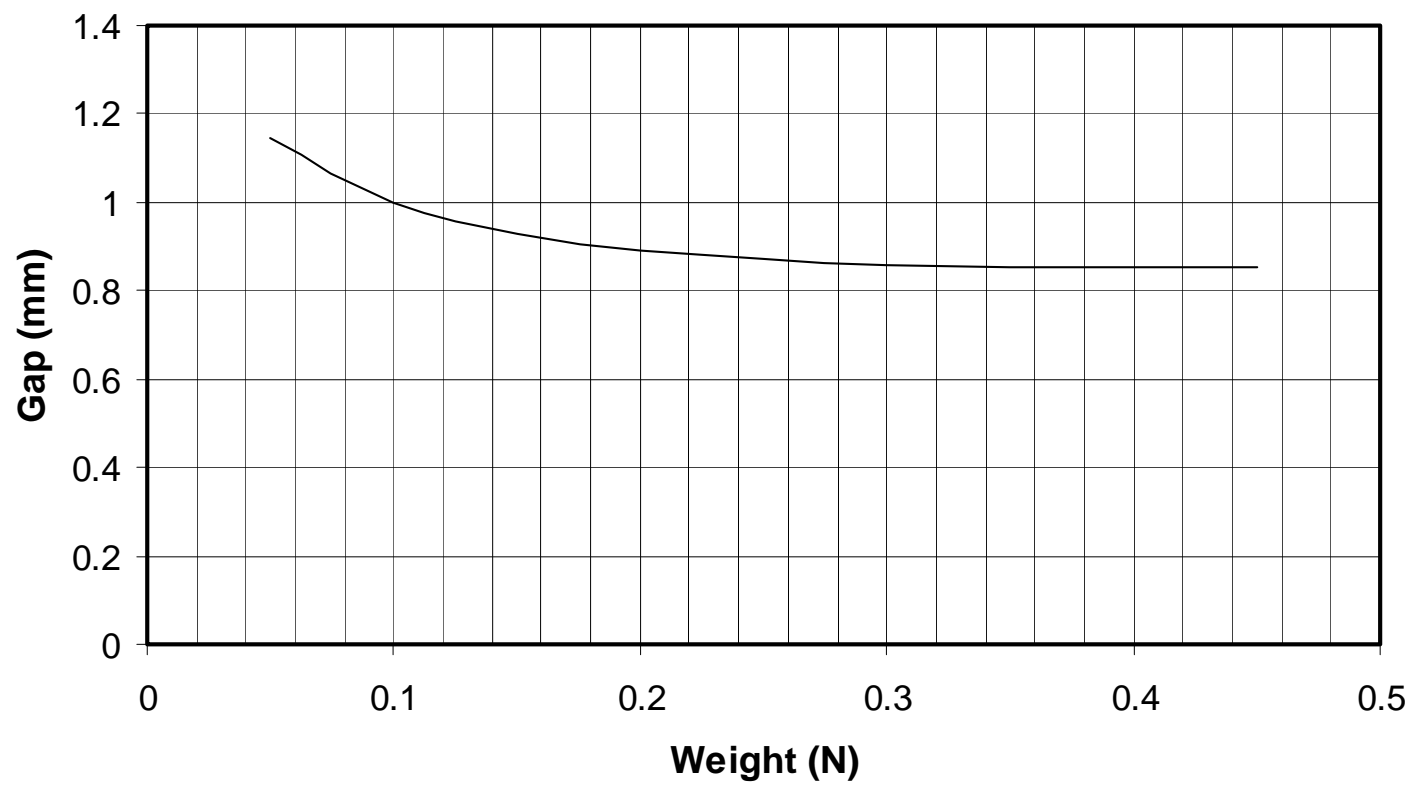

Fig 5.4: Calculated Gap as a Function of Weight. 


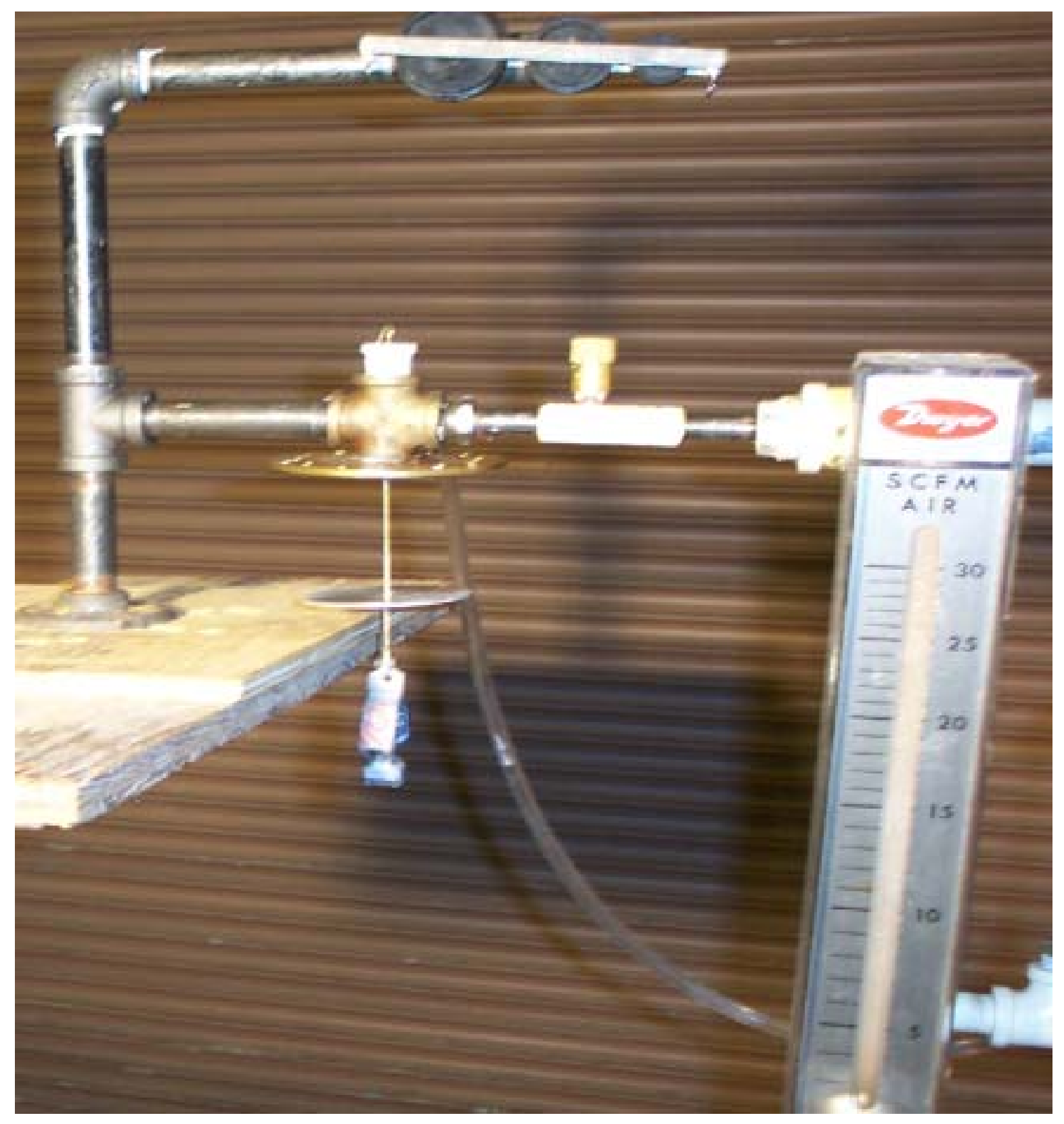

Fig 5.5: Picture of Diaphragm Hanging Freely with no Air Flow. 


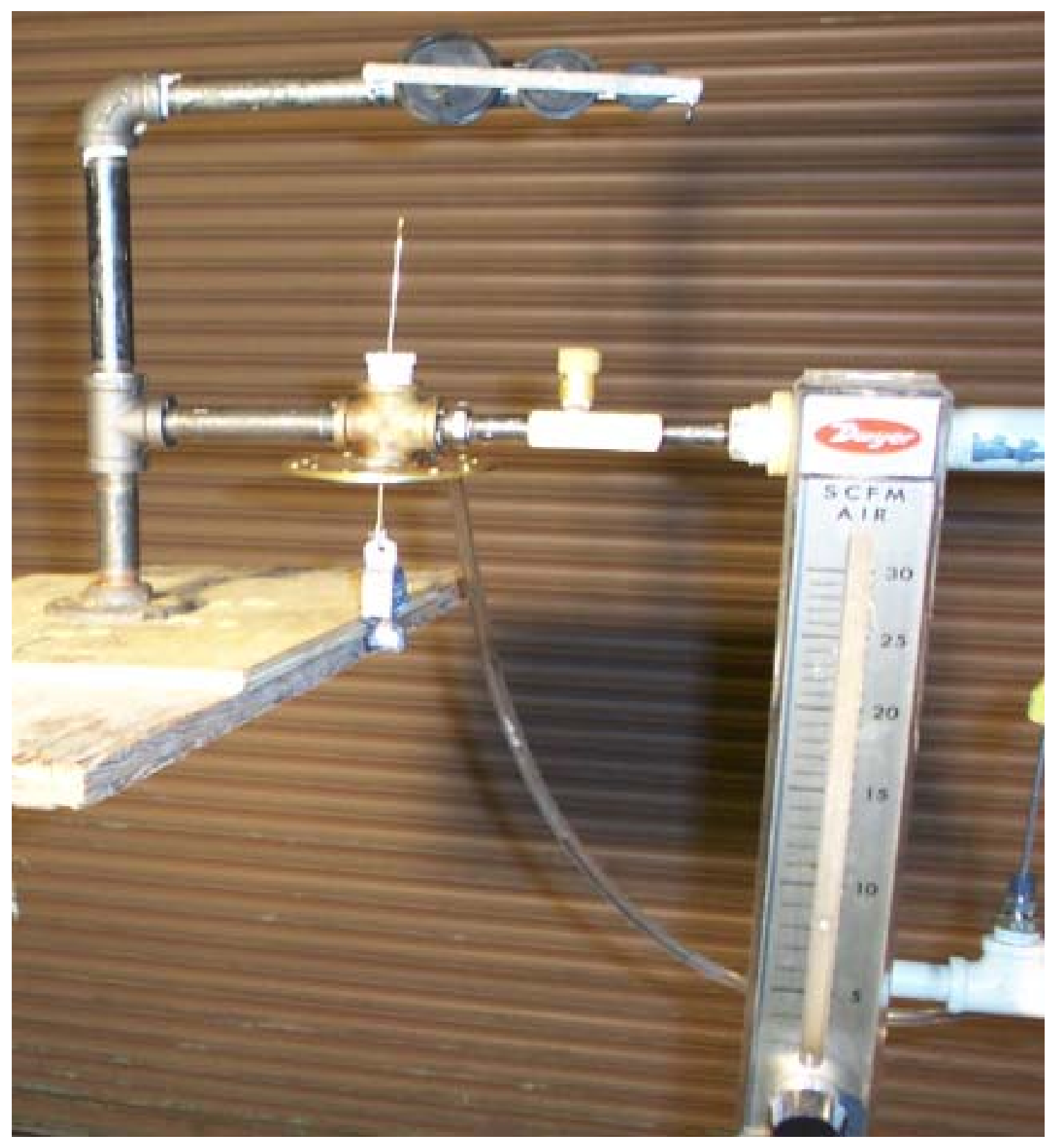

Fig 5.6: Picture of Diaphragm Suspended by Air Flow with a Weight of 43.5 Grams 


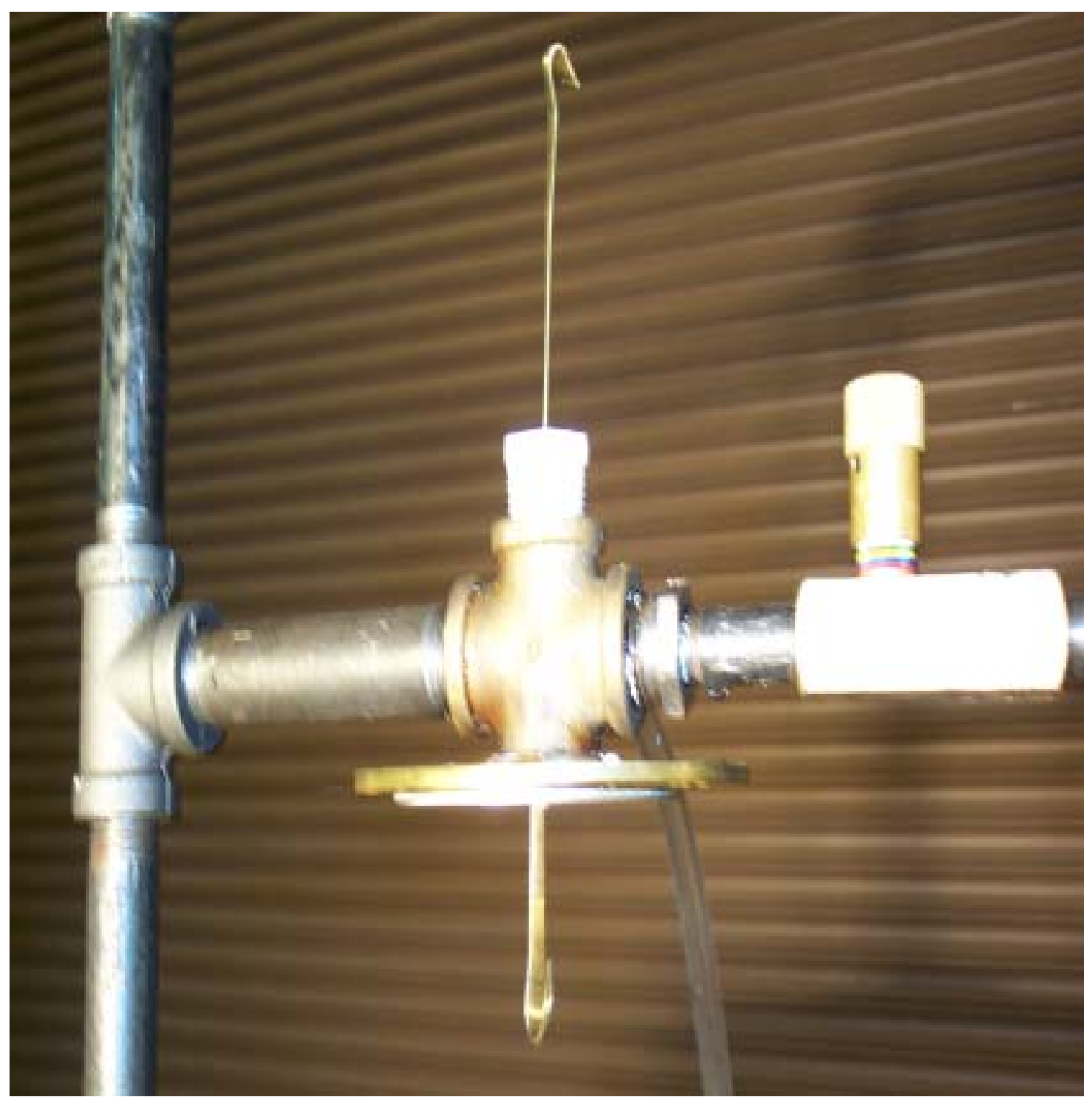

Fig 5.7: Picture of Diaphragm with its Own Weight of 21 Grams Suspended by Air Flow. 


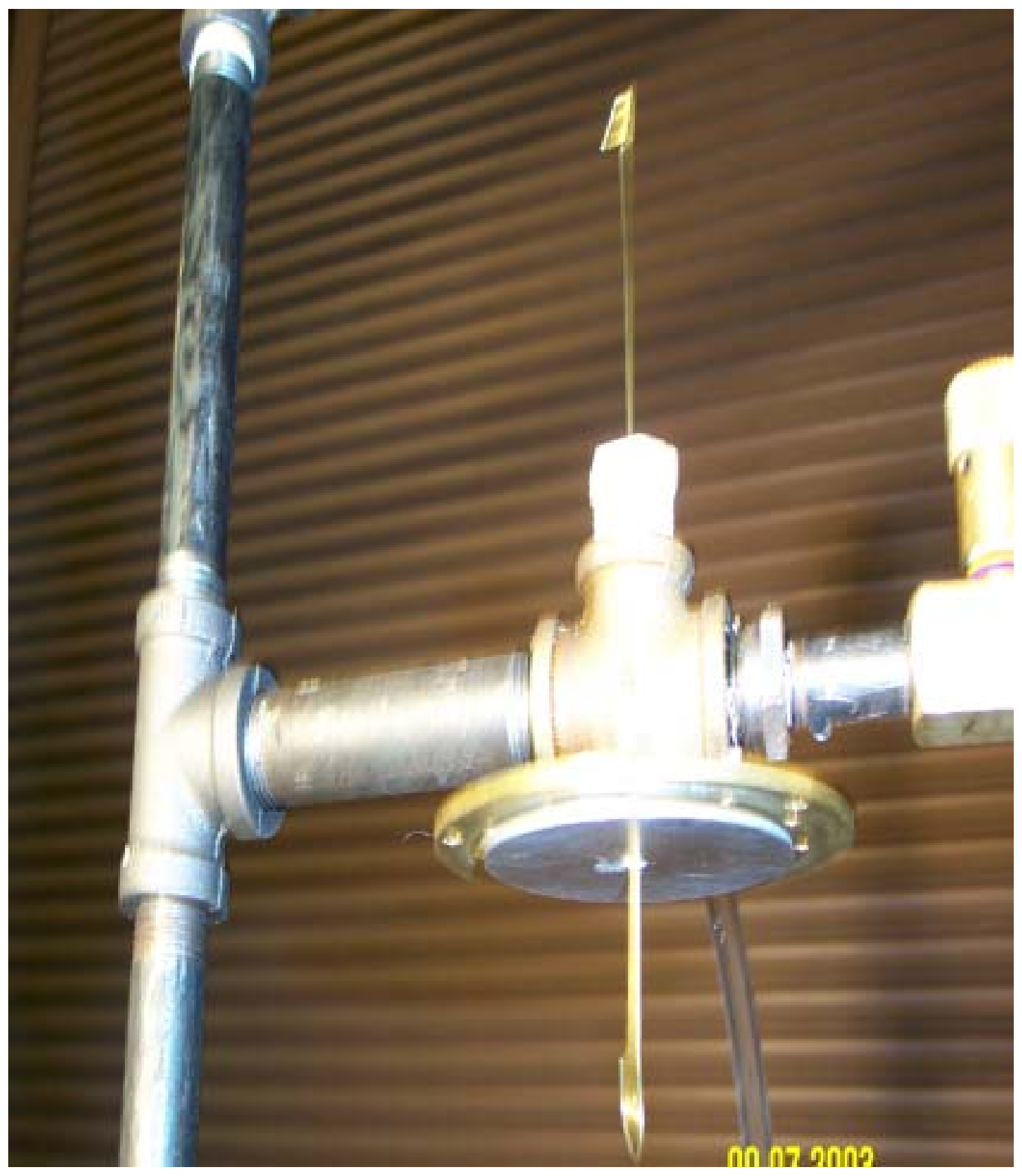

Fig 5.8: Close View of Diaphragm with a Weight of 21 Grams Suspended by Air Flow. 


\section{Chapter 6}

\section{Discussion of Results}

Source/sink flow signal amplifier was calibrated in lab. At various flow rates (cfm), weight (grams) and inlet total pressure (inches of H20) were obtained experimentally. These were then converted to metric units for calculating other variables. Gap d was calculated which showed that the weight carried by the diaphragm increased significantly with the reduction in gap. Flow stagnation force was calculated from the calculated velocity in the pipe which showed that significant force amplification could be obtained relative to this force. Pressure recovery factor was calculated which was found to be constant almost over the entire range. Thus flow guided through a $1 / 2$ inch pipe to a venture like gap does provide significant aerodynamic amplification.

\section{Conclusions}

A large diaphragm three inch in diameter was calibrated in the lab. The suction force on the diaphragm was found to be seven times larger than the force obtained by stagnating the flow in the supply pipe. It was experimentally observed that the gap was almost constant equal $0.85 \mathrm{~mm}$ and independent of weight. The calculated pressure recovery factor was constant almost over the entire range. The source/ sink flow acoustic signal amplifier built at WVU may provide a suitable acoustic amplifier for future instrumentation on acoustic monitoring. 


\section{References}

Bassim, M.N.,and Tangri, K., "Leak Detection in Gas Pipelines using Acoustic Emission",

Proceedings from International Conference on Pipeline Inspection, Edmonton Alberta, pp. 5290544, Canada, 1984.

Brodetsky, Igal and Savic, M., "Leak Monitoring System for Gas Pipelines" Proceedings:

Institute of Electrical and Electronic Engineers, pp 111.17-111.20, New York, 1980.

Flournoy, N.E., and Schroeder, W.W., "Development of a Pipeline Leak Detector", The Journal of Canadian Petroleum Technology, Vol 17, No. 3, pp. 33-36, July 1978.

Huebler, J.E., "Detection of Unauthorized Construction Equipment in Pipeline Right of Ways", Presentation given at National Energy Technology Center Natural Gas Infrastructure Reliability Industry Forums. Morgantown, WV, September 2002.

Jette, N.,Morris, M.S.,Murphy J.C., and Parker, J.G., "Active Acoustic Detection of Leaks in Underground Natural Distribution lines”, Materials Evaluation Journal, Vol 35, Iss. 10, pp.90-96, 99, October 1977.

Jolly, W.D., Morrow, T.B., O’Brien, F.F., Spence, H.F., and Svedeman, S.J., "New Methods for Rapid Detection in Offshore Pipelines", Final Report for U.S. Department of the Interior Minerals Management Service, pp. 1-84, April 1982.

Leis, B.N., Francini, R.B., Stulen, F.B., Hyatt, R.W., and Norman, R., "Real Time Monitoring to Detect Third Party Damage", Proceedings of the Eighth International Offshore and Polar Engineering Conference, Montreal Canada, pp. 34-38, May 1998.

Lee, M. and Lee, J., “Acoustic Emissions Technique for Pipeline Leak Detection”, Key Engineering Vols. 183-187, pp. 887-892, Trans Tech Publications, Switzerland, 2000. 
Moorthy, J.K., "Non Destructive Testing", Proceedings of the $13^{\text {th }}$ World Conference on Non Destructive Testing, Brazil, October 1992.

Parker, J., “Acoustic Detection and Location of Leaks in Underground Natural Gas Disrtibution Lines:, John Hokins APL Digest, V2, N2, pp.90-101, April-June, 1981.

Proakis, J.G and Manolakis, D.G., "Digital Signal Processing”, Prentice Hall, 1996.

Rajtar, J.M., Mutieh, R., and Scott, L.R., "Pipeline leak Detection System for Oil Spills

Prevention”, USDOE and New Mexico Waste Management Education and Research

Consortium, Technical Completion Report, Project \# WERC-01-4-23222, pp. 601-614, August 1994.

Rocha, M.S., “Acoustic Monitoring on Pipeline Leaks” Paper \# 89-0333, ISA, 1989.

Seaford, H., "Acoustic Leak Detection through Advanced Signal Processing Technology", ERA Technology Ltd. Surrey, England, May, 1994.

Shack, W.J. Ellingson, W.A., and Youngdahl, C.A., "Development of a Noninvasive Acoustic Leak Detection Sytem for Large High Pressure Gas Valves", ISA Transactions, Vol 19, No.4, pp. 65-71, 1980.

Sharp, D.B. and Campbell, D.M., "Leak Detection in Pipes using Acoustic Pulse Reflectometry", Acustica, Vol 83, pp. 560-566, 1997.

Southwell, R.V., "Introduction to the theory of elasticity", Oxford University Press, $2^{\text {nd }}$ edition, 1941.

Timoshenko, “Theory of Elastic Stability”, McGraw-Hill, New York, 1961

Varma, V.K., “Gas Pipeline Safety: ORNL’s Role “ Oak Ridge National Lab Review Vol 35, No.2, pp.1-3. http://www.ornl.gov, 2002. 
Watanabe, K., Matukawa, S., Yukawa, H., and Himmelblau, D.M., "Detection and Location of a Leak in a Gas Transport Pipeline by a New Acoustic Method", Hosei University, Department of Instrumentation and Engineering Journal, N1, pp. 129-157, March 1985.

Watanabe, K., and Himmelblau, D.M., "Detection and Location of a Leak in a Gas Transport Pipeline by a New Acoustic Method”, AIChE Journal, V 32, N10, pp. 1690-1701, 1986.

Watanabe, K., Koyama, H., and Ohno, H., "Location of Leaks in a Gas Transport Pipeline by Acoustic Method", Instrument Society of America Technical Paper, N0.87-1106, pp.619-626, 1987.

Wylie, E.B, and Streeter, V.L. with Suo, L., "Fluid Transients in Systems” Prentice Hall, 1993. 